\title{
Measurement of Time-Averaged Particle-Wall Collision Properties Using Particle Tracking Velocimetry CRADA PC93-006, Final Report
}

\author{
Franklin Shaffer \\ Heshmat Massah \\ Jennifer Sinclair \\ Mehrdad Shahnam
}

June 1993 to April 1995

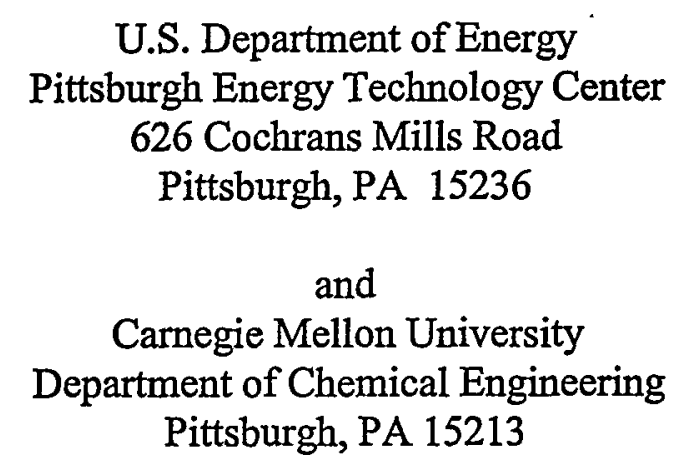

RECEIVED

FEB 261999

OSTI 


\section{Disclaimer}

This report was prepared as an account of work sponsored by an agency of the United States Government. Neither the United States Government nor any agency thereof, nor any of their employees, makes any warranty, express or implied, or assumes any legal liability or responsibility for the accuracy, completeness, or usefulness of any information, apparatus, product, or process disclosed, or represents that its use would not infringe privately owned rights. Reference herein to any specific commercial product, process, or service by trade name, trademark, manufacturer, or otherwise does not necessarily constitute or imply its endorsement, recommendation, or favoring by the United States Government or any agency thereof. The views and opinions of authors expressed herein do not necessarily state or reflect those of the United States Government or any agency thereof. 


\section{DISCLAIMER}

Portions of this document may be illegible in electronic image products. Images are produced from the best available original document. 


\title{
MEASUREMENT OF TIME-AVERAGED PARTICLE-WALL COLLISION PROPERTIES USING PARTICLE TRACKING VELOCIMETRY
}

\author{
Franklin Shaffer \\ U.S. Department of Energy \\ Mail Stop 84-340, P.O. Box 10940 \\ Pittsburgh, PA 15236 \\ Heshmat Massah and Jennifer Sinclair \\ Department of Chemical Engineering \\ Carnegie Mellon University \\ Pittsburgh, PA 15213 \\ Mehrdad Shahnam \\ Gilbert Commonwealth, Inc. \\ Pittsburgh, PA 15236
}

\section{SUMMARY}

This paper describes an experimental facility to measure time-averaged properties of particle-wall collisions. A particle tracking velocimetry (PTV) system measures particle rebound angles and velocities and impact angles and velocities for specific particles. From these measured properties, values of normal and tangential coefficient of restitution are derived. The PTV system rapidly measures thousands of particle-wall collisions enabling determination of time-averaged properties. In this initial work, we use $191 \mu \mathrm{m}$ glass particles colliding with a glass plate at a fixed angle of $17.5^{\circ}$ and a velocity of $17.07 \mathrm{~m} / \mathrm{s}$. Observations are also made of aspherical particles colliding with gross sliding. In the future, this experimental system will be used with particles and wall materials of industrial significance.

\section{INTRODUCTION}

Particle-wall collisions play an important role in many industrial systems. Some examples are particle deposition in combustion systems, erosion of turbine blades in jet engines by airborne particulates, fluidization for chemical processing, and the pneumatic transport of particles from one location to another.

Computer simulation of particulate flows is a powerful design tool for these systems. Whether the computer simulations track individual particles or treat the particle phase as a continuum, the manner in which the collisions are described greatly influences the flow predictions $[1,2]$. The goal of this project is to provide the empirical data for particle-wall collisions needed to enhance the predictions of computer simulations. What is required are timeaveraged properties of particle rebound angles and velocities as a function of impact angle and velocity for a wide range of particle and wall materials. This work is concerned with particles driven primarily by inertia and drag: particle sizes in the range of $10-500 \mu \mathrm{m}$ and velocities on the order of $10 \mathrm{~m} / \mathrm{s}$ or higher.

In the past, descriptions of particle-wall collisions were limited to data for normal coefficient of restitution [3]. This was a simple measurement of the ratio of rebound and impact velocities normal to a wall. However, in actual industrial systems, particle-wall collisions are much more complex than described by the normal coefficient of restitution. Particles usually impact at angles other than normal to a wall. The tangential coefficient of restitution (ratio of rebound to impact velocity tangential to a wall) may not be the same as the normal coefficient of restitution. For rough walls or aspherical particles, rebound angles and velocities may vary considerably for a given impact velocity and angle, i.e., the rebound scattering is diffuse rather than specular.

Recently, a few efforts have produced data more descriptive of particle-wall collisions. Tabakoff et al. [4] used laser doppler velocimetry (LDV) to make point measurements of two components of particle velocity near a wall. 
While LDV quickly generates large numbers of data, it cannot follow the same particle before and after a collision. More recently Foerster et al. [5] measured particle trajectories before and after a collision. Their system is also capable of measuring particle spin for large $(3.18$ and $5.99 \mathrm{~mm})$ particles. However, it is yet to produce large numbers of measurements for determination of time-averaged properties.

In this paper, we describe an experiment that measures the parameters required for input into computer simulations: time-averaged values of rebound angle and velocity as a function of impact angle, impact velocity, particle type, and wall material. The experimental system was developed in the Flow Analysis Facility of the Department of Energy's Pittsburgh Energy Technology Center by Shaffer et al. [6,7]. A particle tracking velocimetry (PTV) system measures the trajectory of a particle, and velocity along the trajectory, for a single particle before and after collision. With the PTV system, a pulsed laser produces a multiple-exposure picture of a particle along its trajectory. By measuring the displacement of successive particle images, the particle trajectory and velocity along a trajectory are determined - including a particle's trajectory before and after collision with a wall. The system is capable of measuring thousands of trajectories in a few, hours allowing determination of time-averaged properties.

The particle-wall collisions are setup in a wind tunnel providing a collision field with accurately controlled conditions. The particles arrive at a constant velocity and, within the measurement region, their trajectories are affected only by collision with a wall. The collision rate is high enough to measure large numbers of collisions within reasonably short times.

For the initial tests described in this paper, the independent experimental parameters (wall material, particle type, impact velocity and impact angle) are not varied. Rather, ideal materials, $191 \mu \mathrm{m}$ glass spheres and a smooth glass plate, are used. The impact velocity and angle are fixed at $17.07 \mathrm{~m} / \mathrm{s}$ and $17.5^{\circ}$. In future experiments, data will be gathered for a variety of wall materials, particle types, impact velocities, and impact angles of industrial significance.

\section{EXPERIMENTAL}

Figure 1 (on the following page) shows the configuration of the experimental equipment. In the test section of the wind tunnel, glass particles are brought into collision at the center of a smooth glass plate. The particles are injected at a constant velocity by pneumatic transport through a $6 \mathrm{~mm}$ tube. The injection tube is placed $10 \mathrm{~cm}$ above the glass plate and is tilted downward about $20^{\circ}$. Particles are fed into the pneumatic transport line at a steady rate using a feed regulator and a screwfeeder in series. To ensure that particles reach a constant velocity before collision, the particle injection point is far upstream, more than 200 tube diameters, of the injection point.

The glass particles have a mean size of $191 \mu \mathrm{m}$ and are sieved to a size range from 175 to $208 \mu \mathrm{m}$. The particle density is $2.47 \mathrm{~g} / \mathrm{cc}$. Most of the particles, approximately $95 \%$, appear to be nearly perfect spheres. However, up to about $5 \%$ of the particles are defective, appearing either elliptical or as fragmented pieces of glass. Figure 2 shows a microphotograph of the glass spheres at a magnification of $5 \mathrm{X}$.

The dimensions of the glass plate are $0.275 \mathrm{~m} \times 0.275 \mathrm{~m}$ with a thickness of $3 \mathrm{~mm}$. Support posts are placed at the corners of the plate. The size of the plate and the distance of the support posts from the impact point are sufficient to ensure that the collisions are independent of the finite plate dimensions. This was verified based on the criteria given by Sondergaard et al. [8].

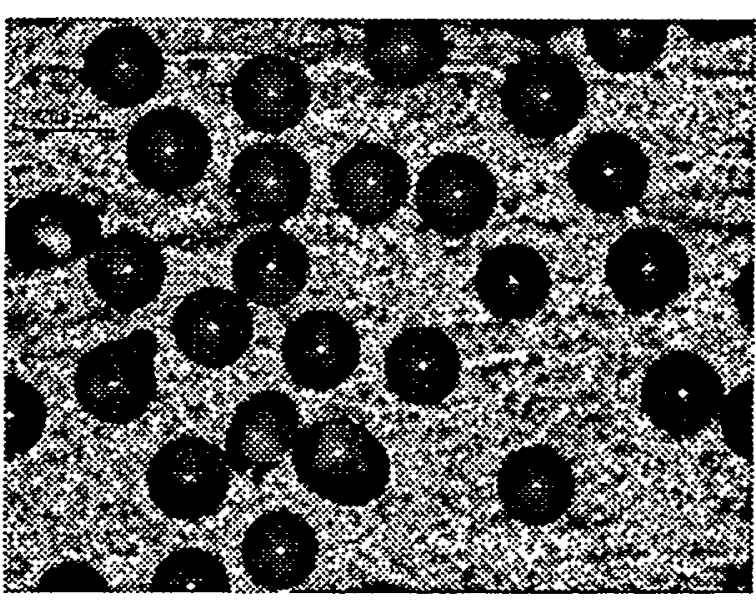

Figure 2. Microphotograph of glass particles at a magnification of $5 X$. 

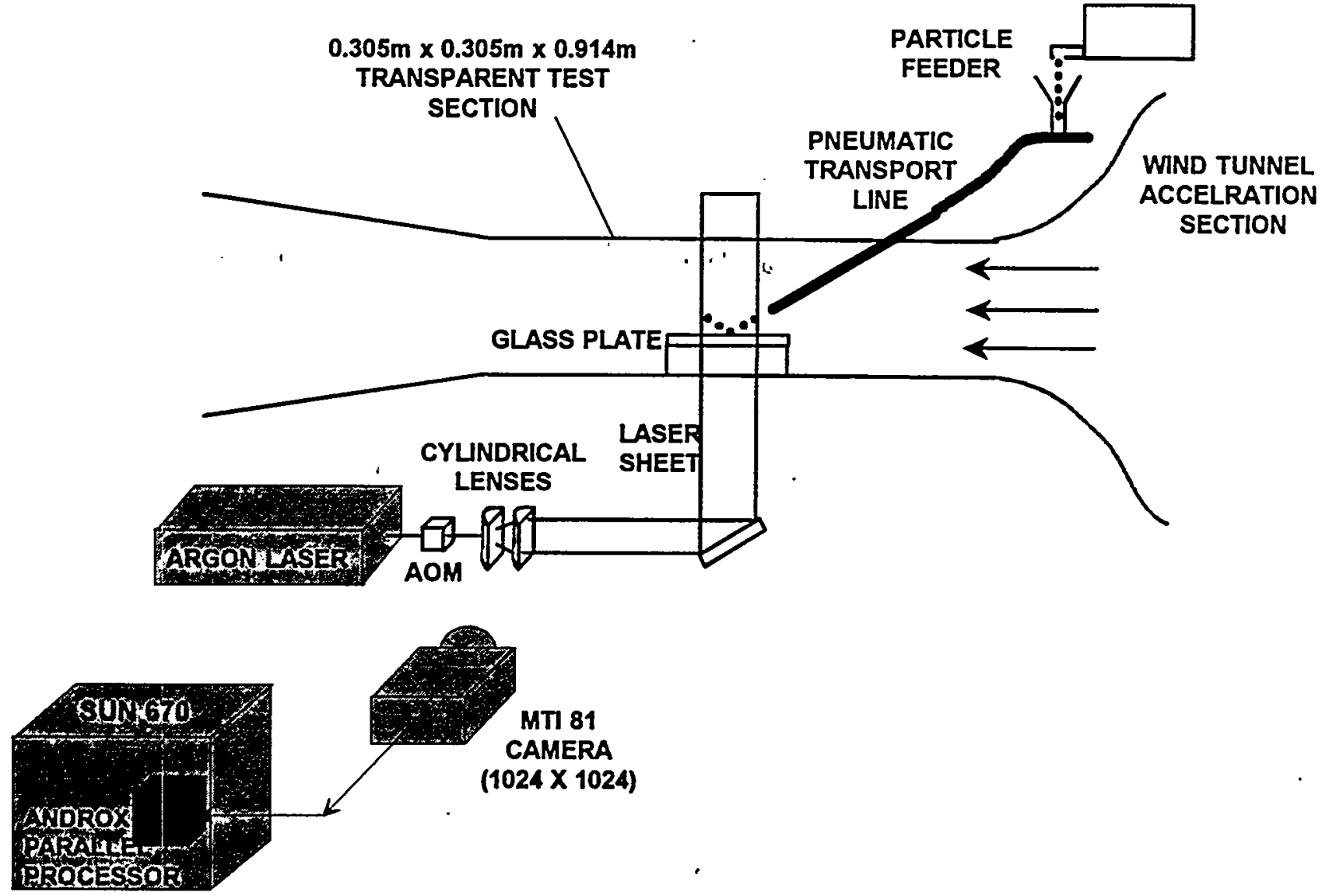

Figure 1. Schematic of experimental system.

To minimize aerodynamic drag on the particles, the air velocity in the wind tunnel was set to minimize slip velocity between the particles and air. This was verified using a two-component laser doppler velocimeter (LDV) to measure air and particle velocities. The maximum slip velocity between the air and particles was verified to be less than $1.3 \mathrm{~m} / \mathrm{s}$ within the region where particle collisions are measured. This gives a Stokes number of 500 (based on the particle response time of $0.13 \mathrm{~s}$ and a particle transit time through the measurement region of 300$400 \mu s$ ) ensuring that the particle response to drag is negligible.

Since particle spin is not measured with the PTV system, it is also important to ensure that particle spin doesn't influence the measurements. Observations of some of the aspherical particles, for which rotation can be seen, indicates that particle spin is low, less than $1000 \mathrm{rpm}$. Even if the particles were spinning at very high rotation speeds, for example more than $10,000 \mathrm{rpm}$, the actual speed of the particle surface (the product angular velocity and particle radius) due to rotation is less than $1 \%$ of the linear velocity of the particle. Therefore, particle spin is assumed to have a negligible effect on the measured collision parameters. For larger particles and slower velocities, such as those used by Foerster et al. [5], (3.18 and $5.99 \mathrm{~mm}$ at $<2 \mathrm{~m} / \mathrm{s})$, lower particle spin can have a significant effect on the collisions parameters.

The beam from an acousto-optically modulated $7 \mathrm{~W}$ argon laser is transmitted through a series of cylindrical lenses to form a thin $(1 \mathrm{~mm})$ sheet of pulsed laser light. The beam is directed upward through the base of the test section in the wind tunnel and through the glass plate to illuminate the particle-wall collisions. The pulse repetition rate was set at $25 \mathrm{KHz}$ with a pulse duration of $5 \mu \mathrm{s}$. 
As particles pass through the light sheet they scatter light into a high-resolution (1024 x 1024 pixel) video camera positioned at a right angle to the laser sheet. This produces a multiple exposure picture showing a series of images of a particle along its trajectory. Figure 3 shows an example picture of a particle colliding with the glass plate. The field-of-view size for these measurements was $28.38 \times 21.57 \mathrm{~mm}$. The PTV pictures are digitized at 30 pictures/second with 8-bit (256 levels) gray scale resolution into a SUN 670 computer with an ANDROX parallel image processor. Only a $2.69 \mathrm{~mm}$ region of the PTV picture near the wall (as shown in Figure 3) is permanently stored. Particle images are detectable within one particle image diameter of the plate surface.

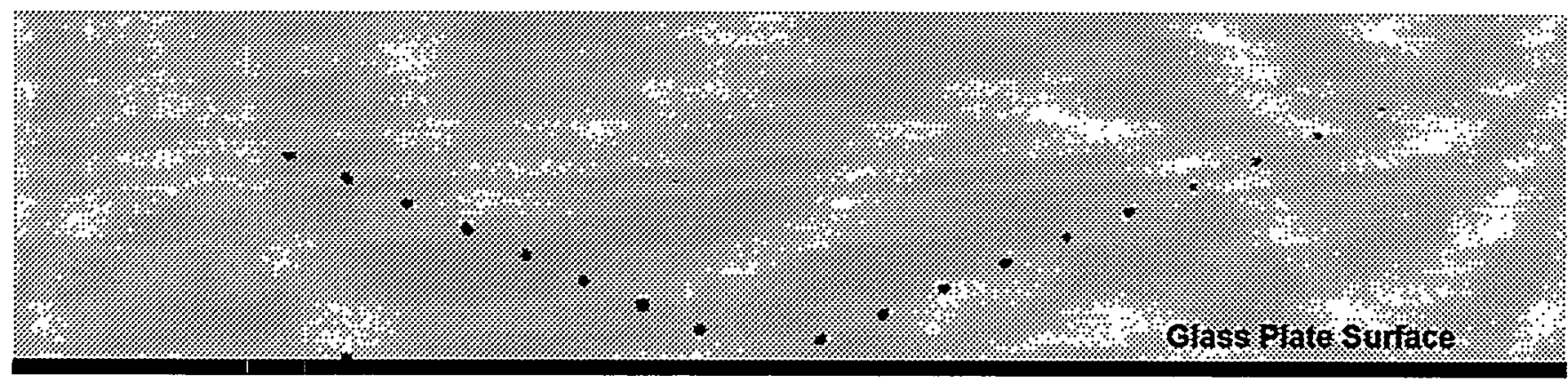

Figure 3. Typical particle-wall collision. A black line is added to show the location of the glass plate.

Lighting conditions are set so that the raw digital pictures have a uniform background gray level. This was accomplished by increasing the camera black level far above the background level. With a uniform background, the image compression efficiency is better than $95 \%$; this is necessary to economically store potentially millions of images.

Software has been developed at PETC to automatically analyze multiple-exposure pictures of particle trajectories $[9,10]$. The first step in the image analysis is recognition of particle images and calculation of image centroids. The next step is to recognize groups of centroids as belonging to an impact or rebound trajectory. This is achieved using an iterative Kalman filtering algorithm with a likelihood function based on knowledge of the number of particle images along a trajectory. Next, the impact and rebound trajectories are extrapolated to their intersection points with the glass plate. If the plate intersection points of a pair of impact and rebound trajectories are close within an adjustable tolerance they are assumed to be from the same particle. For this work the tolerance was set at two particle diameters. The tight tolerance restricts the data to particles with instantaneous contacts with the plate; particles that slide or roll upon contact are automatically excluded. Figure 4 shows an example of gross sliding upon contact. This occurs only for a small fraction of the particle-wall collisions. The last step in the analysis process involves calculation of angles, velocities, and restitution coefficients. The entire image acquisition and analysis process takes on the order of one second per picture. This enables rapid analysis of thousands of trajectories required for statistical convergence.

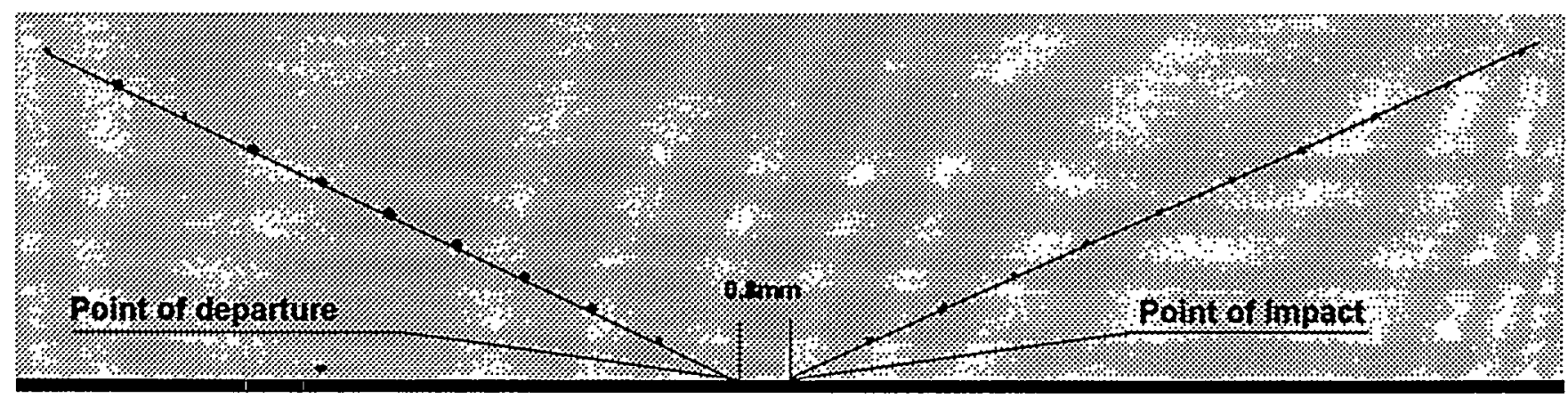

Figure 4. Picture of a particle collision involving visible sliding. 
The experimental uncertainties in collision parameters (velocity, angle, and restitution coefficients) arise from two factors: uncertainties in the basic measurements of distance with the imaging system and uncertainties in the timing of laser pulses. The digital pulse generator used in this experiment has one nanosecond resolution, making the timing uncertainty negligible. The uncertainty in distance are mainly due to the pixel resolution of the imaging system and the resolution of the scale used to calibrate the imaging system. For this PTV system and experimental conditions, the total uncertainty in distance measurement is $\pm 31 \mu \mathrm{m}$. This translates into an uncertainty of \pm 0.21 $\mathrm{m} / \mathrm{s}$ in velocity, $\pm 0.6^{\circ}$ in angle, $\pm 5 \%$ in normal restitution coefficient and $\pm 2 \%$ in tangential coefficient of restitution.

\section{RESULTS AND DISCUSSION}

In this paper, we described an experimental facility to measure time-averaged properties of particle-wall collisions. A particle tracking velocimetry (PTV) system measures particle rebound angles and velocities and impact angles and velocities for specific particles. From these measured properties, values of normal and tangential coefficient of restitution are derived. The PTV system rapidly measures thousands of particle-wall collisions, enabling determination of time-averaged properties.

Figures 5 and 6 show the distributions of rebound angles and rebound velocities for the $191 \mu \mathrm{m}$ glass particles colliding with the glass plate. The impact angle was $17.5^{\circ} \pm 0.6^{\circ}$ and the impact velocity was $17.07 \pm 0.21 \mathrm{~m} / \mathrm{s}$. The mean rebound angle was $17.94^{\circ} \pm 0.6^{\circ}$ with a standard deviation of $1.84^{\circ}$ and the mean rebound velocity was $16.10 \pm 0.21 \mathrm{~m} / \mathrm{s}$ with a standard deviation of $1.21 \mathrm{~m} / \mathrm{s}$.

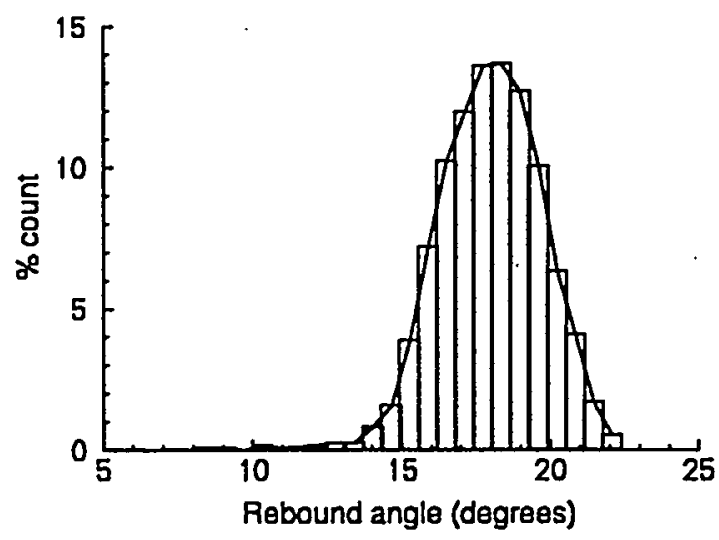

Figure 5. Histogram of rebound angle.

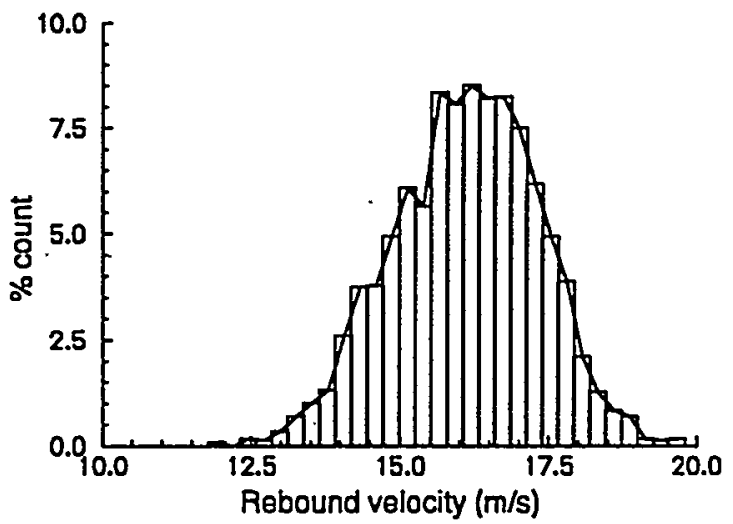

Figure 6. Histogram of rebound velocity.

Figures 7 and 8 show the distributions of normal and tangential coefficient of restitution. Since the coefficient of restitution data is derived from ratios of impact and rebound angles, the values can only be properly derived by tracking the same particle before and after collision. Other techniques such as LDV do not follow the same particle before and after collision and thus cannot give true values of coefficient of restitution. The mean value for tangential and normal coefficient of restitution are $0.94 \pm 0.018$ and $0.97 \pm 0.05$, respectively. The standard deviations for tangential and normal coefficient of restitution are 0.02 and 0.07 , respectively.

The data in Figures 5 through 8 is derived for measurement of 2265 particle wall collisions. To the knowledge of the authors, this is the first measurement of a large enough number of particle-wall collisions to determine timeaveraged properties by following each particle before and after collision.

During the experiments, occasional rolling or sliding of particles upon collision with the glass plate was observed. We believe this behavior happens only with the small fraction of the glass particles that are non-spherical. The non-sphericity of the particle images for sliding trajectories confirms this. 


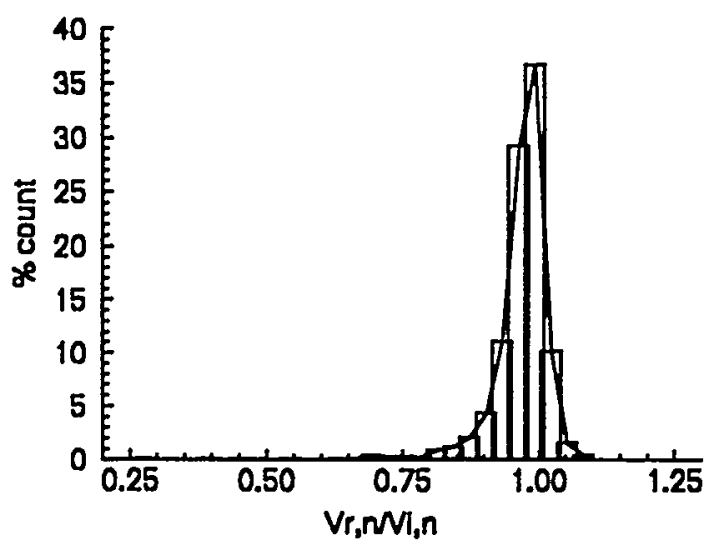

Figure 7. Histogram of ratio of normal component of rebound velocity to normal component of impact velocity.

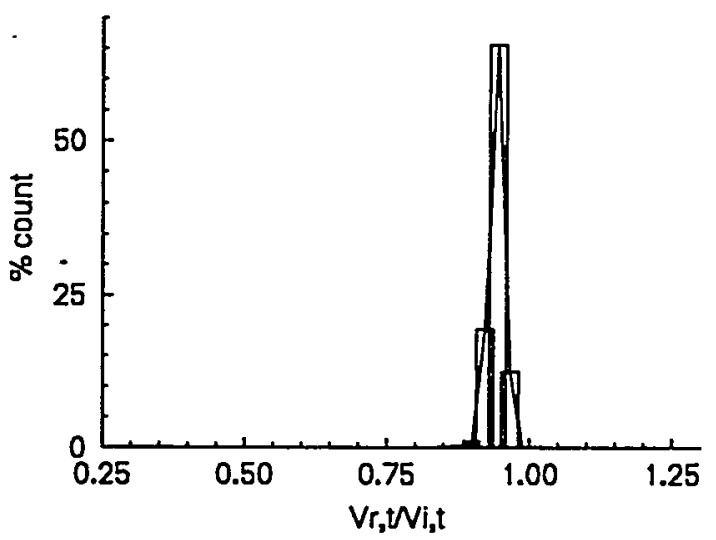

Figure 8. Histogram of ratio of tangential component of rebound velocity to tangential component of impact velocity.

In the future this experimental system will be used with particles and wall materials of industrial significance. Eventually a data bank will be produced for a wide range of particle types, wall materials and flow conditions.

\section{ACKNOWLEDGMENTS}

This work was done under Cooperative Research and Development Agreement No. PC93-006 between the U.S. Department of Energy and Carnegie Mellon University (CMU). The authors from CMU wish to gratefully acknowledge funding from the Amoco Oil Company. The important contributions of Bala Kumar of the CMU Robotics Institute and R. Srinivasan of EASI Inc. with image analysis are also acknowledged.

\section{REFERENCES}

1. Yasuna, J., Bolio, E., Gamwo, I., and J. Sinclair, AIChE Symposium Series, 89 (1993) 184.

2. Louge, M., Mastorakos, E., and J. Jenkins, J. Fluid Mech., 231 (1991) 345.

3. Goldsmith, W. "Impact - The Theory and Behaviour of Colliding Solids," Edward Arnold (Publishers) London (1960).

4. Tabakoff, W. and Malak, M.F., "Laser Measurement of Fly Ash Rebound Parameters for Use in Trajectory Calculations," J. Turbomachinary, Vol. 109, Oct. 1987.

5. Foerster, S., Louge, M., Chang, H., and K. Allia, Physics of Fluids A, submitted for publication.

6. Shaffer, F.D., Ekmann, J.M., and Ramer, E.R., "Development of Pulsed-Laser Velocimetry Systems Utilizing Photoelectric Image Sensors," Proc. of the AIAA/ASME/SIAM/APS First National Fluid Dynamics Congress, Cincinnati, OH, July 1988.

7. Shaffer, F and E. Ramer, "Pulsed laser imaging of particle-wall collisions," in Proceedings of the International Conference on the Mechanics of Two-Phase Flow, 12-15 June 1989, Taipai, Taiwan (1989) 116.

8. Sondergaard, R., Chaney, K., and C. Brennen, ASME J. of Applied Mechanics, 57 (1990) 694.

9. Ramer, E. and F. Shaffer, Applied Optics, 31 (1990) 779.

10. Singh, R., Shaffer, F., and Borovetz, H., "Fluorescent Image Tracking Velocimetry Algorithms for Quantitative Flow Analysis in Artificial Organs," Int. Symp. on Electronic Imaging, San Jose, CA, January 1993. 


\title{
NON-INTRUSIVE MEASUREMENTS OF PARTICLE-WALL COLLISION PROPERTIES
}

\author{
Heshmat Massah ${ }^{1}$, Franklin Shaffer ${ }^{2}$, Jennifer Sinclair ${ }^{1}$ and Mehrdad Shahnam ${ }^{3}$
}

1. Department of Chemical Engineering, Carnegie Mellon University, Pittsburgh, PA 15213

2. U.S. Department of Energy, Mail Stop 84-340, P.O. Box 10940, Pittsburgh, PA 15236

3. Gilbert Commonwealth, Inc., Library, PA 15236

\section{SUMMARY}

The properties of particle-wall collisions were measured using a particle image tracking velocimetry (PTV) system capable of rapidly measuring thousands of particle-wall collisions. The measured properties are rebound angles and velocities and incidence angles and velocities for a specific particle. From these measured properties the time-averaged coefficients of restitution and friction, both normal and tangential, are derived. In this initial work we use $191 \mu \mathrm{m}$ glass particles colliding with a glass plate at a mean angle of $17.5^{\circ}$ and a mean velocity of $17.07 \mathrm{~m} / \mathrm{s}$. Values of $0.97,0.94$ and 0.027 were found for normal and tangential coefficient of restitution and coefficient of friction, respectively. This experimental system is also being used with other particles and wall materials of industrial significance.

\section{INTRODUCTION}

Particle-wall collisions play an important role in many industrial systems. Some examples are particle deposition in combustion systems, erosion of turbine blades in jet engines by airborne particulates, fluidization for chemical processing, and the pneumatic transport of particles from one location to another.

Computer simulation of particulate flows is a powerful design tool for these systems. Whether the computer simulations track individual particles or treat the particle phase as a continuum, the manner in which the collisions are described greatly influences the flow predictions [1,2]. The goal of this project is to provide the empirical data for particle-wall collisions needed to enhance the predictions of computer simulations. What is required are time-averaged properties of particle rebound angles and velocities as a function of incidence angle and velocity for a wide range of particle and wall materials.

In the past, descriptions of particle-wall collisions were limited to data for normal coefficient of restitution [3]. This was a simple measurement of the ratio of rebound and incidence velocities normal to a wall. However, in actual industrial systems, particle-wall collisions are much more complex than described by the normal coefficient of restitution. The tangential coefficient of restitution (ratio of rebound to incidence velocity tangential to a wall) may not be the same as the normal coefficient of restitution. For rough walls or aspherical particles, rebound angles and velocities may vary considerably for a given incidence velocity and angle, i.e., the rebound scattering is diffuse rather than specular.

Tabakoff et al. [4] used laser Doppler velocimetry (LDV) to make point measurements of two components of particle velocity near a wall. While LDV quickly generates a large quantity of data, it cannot follow the same particle before and after a collision. Unless the incidence angle and velocity are confined to a narrow range, LDV cannot provide an accurate measure of coefficients of restitution and friction. More recently Foerster et al. [5] measured particle trajectories before and after a collision using frame-to-frame video 
tracking. Their system is capable of releasing particles without spin and is more suitable for large particles $(>1 \mathrm{~mm})$ and low velocities $(<2 \mathrm{~m} / \mathrm{s})$. However, it is yet to produce large numbers of measurements for determination of time-averaged properties. In 1988 and 1989, Shaffer and Ramer [6,7] described a PTV system for measurement of particle-wall collisions. The PTV technique generates true values of coefficient of restitution since it tracks a specific particle before and after a collision. Recently, Sommerfeld presented measurements of large quantities of particle-wall collisions with rough surfaces using a PTV system [8].

In this paper, we describe an experiment that quickly measures the particle-wall collision parameters required for input into computer simulations: time-averaged values of rebound angle and velocity as a function of incidence angle, incidence velocity, particle type, and wall material. The experimental system was developed in the Flow Analysis Facility of the Department of Energy's Pittsburgh Energy Technology Center by Shaffer et al. [6,7]. A particle tracking velocimetry (PTV) system measures the trajectory of a particle, and velocity along the trajectory, for a single particle before and after collision. With the PTV system, a pulsed laser produces a multiple-exposure picture of a particle along its trajectory. By measuring the displacement of successive particle images the particle trajectory and velocity along a trajectory are determined - including a particle's trajectory before and after collision with a wall. The system is capable of measuring thousands of trajectories in a few hours allowing determination of time-averaged properties.

The particle-wall collisions are setup in a wind tunnel providing a collision field with accurately controlled conditions. The particles arrive at a constant velocity and, within the measurement region, their trajectories are affected only by collision with a wall. The collision rate is high enough to measure large numbers of collisions within reasonably short times.

For the initial tests described in this paper, the independent experimental parameters (wall material, particle type, incidence velocity and incidence angle) are not varied. Rather, ideal materials, 175-208 $\mu \mathrm{m}$ glass spheres and a smooth glass plate, are used. The incidence velocity and angle are about $17 \mathrm{~m} / \mathrm{s}$ and $17.5^{\circ}$. Experiments are now underway to gather data for wall materials, particle types, incidence velocities and incidence angles of industrial significance.

\section{EXPERIMENTAL PROCEDURE}

Figure 1 shows the configuration of the experimental equipment. In the test section of the wind tunnel, glass particles are brought into collision at the center of a smooth glass plate. The particles are driven by pneumatic transport through a $6 \mathrm{~mm}$ tube under a constant pressure of $40 \mathrm{psig}$. The injection tube is placed 10 $\mathrm{cm}$ above the glass plate and is tilted downward about $20^{\circ}$. Particles are fed into the pneumatic transport line at a steady rate using a feed regulator and a screwfeeder in series.

The glass particles have a mean size of $191 \mu \mathrm{m}$ and are sieved to a size range from 175 to $208 \mu \mathrm{m}$. The particle density is $2.47 \mathrm{~g} / \mathrm{cc}$. Most of the particles, approximately 95\%, appear to be nearly perfect spheres. However, up to about $5 \%$ of the particles are defective, appearing either elliptical or as fragmented pieces of glass. Figure 2 shows a microphotograph of the glass spheres at a magnification of $5 \mathrm{X}$.

The dimensions of the glass plate are $0.27 \mathrm{~m} \mathrm{x} 0.27 \mathrm{~m}$ with a thickness of $3 \mathrm{~mm}$. Support posts are placed at the corners of the plate. The size of the plate and the distance of the support posts from the incidence point are sufficient to ensure that the collisions are independent of the finite plate dimensions. This was verified based on the criteria given by Sondergaard et al. [9]. 

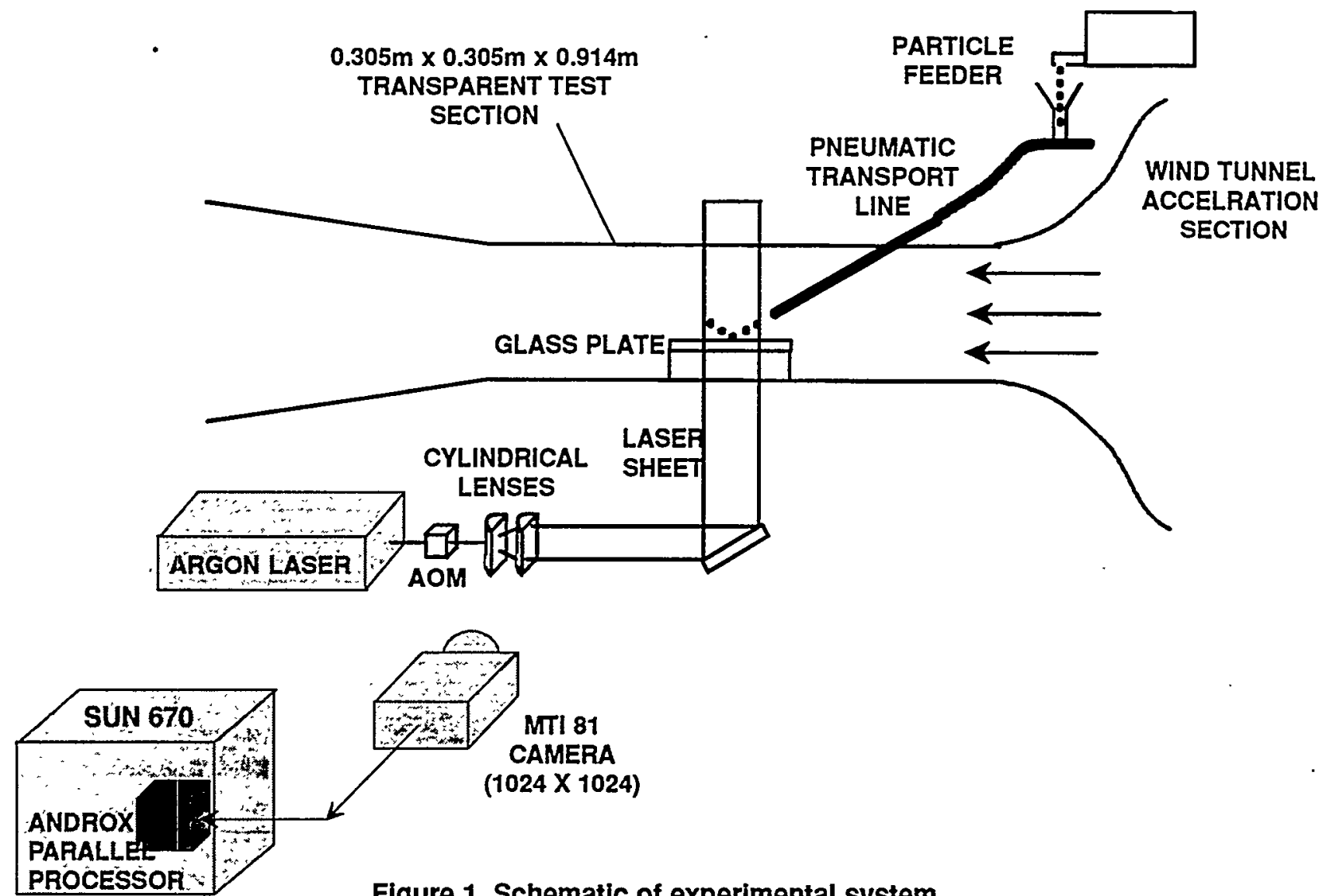

Figure 1. Schematic of experimental system.

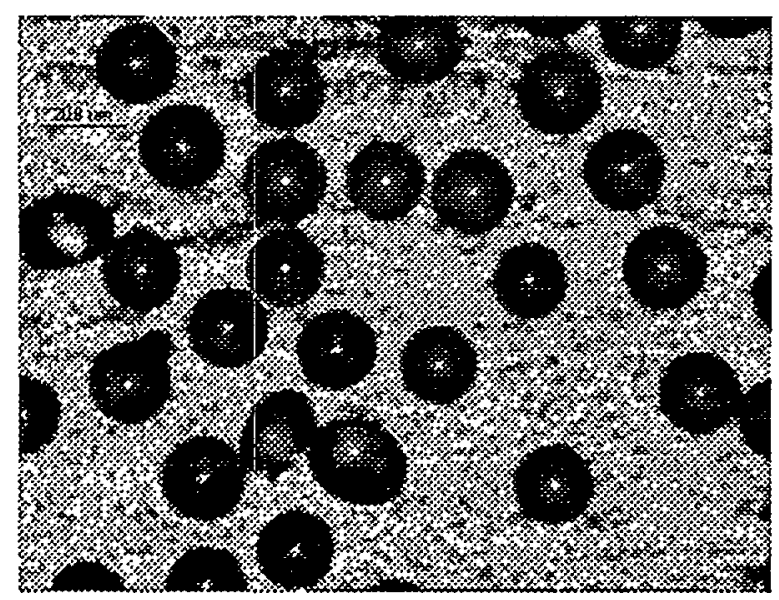

Figure 2. Microphotograph of glass particles at a magnification of $5 \mathrm{X}$.
To minimize aerodynamic drag on the particles, the air velocity in the wind tunnel was set to minimize slip velocity between the particles and air. This was verified using a two-component laser Doppler velocimeter (LDV) to measure air and particle velocities. The maximum slip velocity between the air and particles was verified to be less than $1.3 \mathrm{~m} / \mathrm{s}$ within the region where particle collisions are measured. This gives a Stokes number of 500 (based on the particle response time of $0.13 \mathrm{~s}$ and a particle transit time through the measurement region of $300-400 \mu \mathrm{s}$ ) ensuring that the particle response to drag is negligible.

Since particle spin is not measured with the PTV system, it is also important to ensure that particle spin does not influence the measurements. Even if the particles were spinning at very high rotation speeds, for example more than $10,000 \mathrm{rpm}$, the actual speed of the particle surface (the product of angular velocity and particle radius) due to rotation is less than $1 \%$ of the linear velocity of the particle. Therefore, it is assumed that particle spin has a negligible effect on the measured collision parameters. For larger particles and slower velocities, such as those used by Foerster et al. [5], (3.18 and $5.99 \mathrm{~mm}$ at $<2 \mathrm{~m} / \mathrm{s}$ ), particle spin can have a significant effect on the collisions parameters. 
The beam from an acousto-optically modulated $7 \mathrm{~W}$ argon laser is transmitted through a series of cylindrical lenses to form a thin $(1 \mathrm{~mm})$ sheet of pulsed laser light. The beam is directed upward through the base of the test section in the wind tunnel and through the glass plate to illuminate the particle-wall collisions. The pulse repetition rate was set at $25 \mathrm{KHz}$ with a pulse duration of $5 \mu \mathrm{s}$.

As particles pass through the light sheet they scatter light into a high-resolution (1024 $\times 1024$ pixel) video camera positioned at a right angle to the laser sheet. This produces a multiple exposure picture showing $a$ series of images of a particle along its trajectory. Figure 3 shows an example picture of a particle colliding with the glass plate. The field-of-view size for these measurements was $28.38 \times 21.57 \mathrm{~mm}$. The PTV pictures are digitized at 30 pictures/second with 8-bit (256 levels) gray scale resolution into a SUN 670 computer with an ANDROX parallel image processor. Only a $2.69 \mathrm{~mm}$ region of the PTV picture near the wall (as shown in Figure 3) is permanently stored. Particle images are detectable within one particle image diameter of the plate surface.

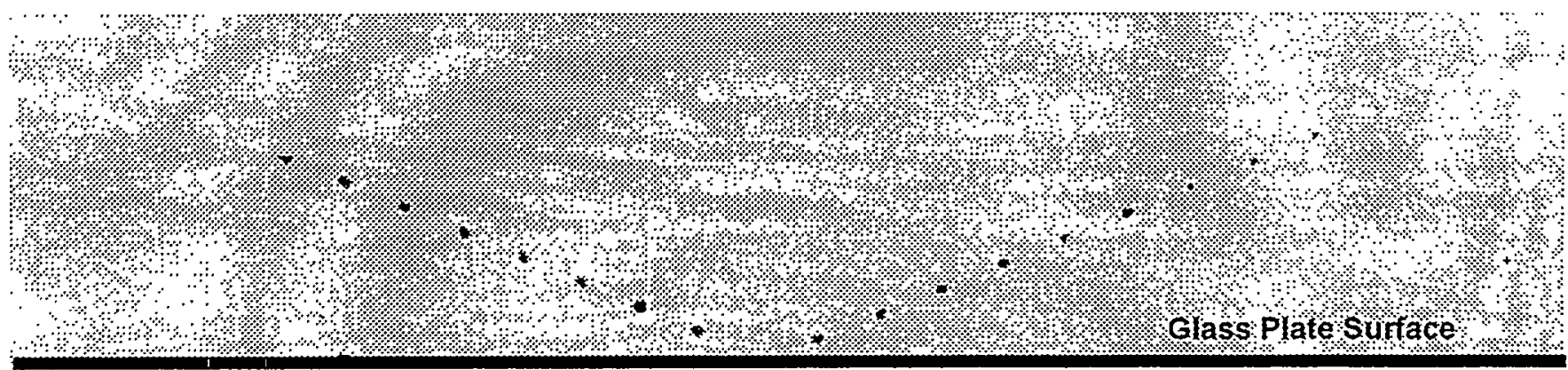

Figure 3. Typical particle wall collision. A black line is added to show the location of the glass plate.

Lighting conditions are set so that the raw digital pictures have a uniform background gray level. This was accomplished by increasing the camera black level far above the background level. With a uniform background, the image compression efficiency is better than $95 \%$; this is necessary to economically store thousands of images.

Software has been developed at PETC to automatically analyze multiple-exposure pictures of particle trajectories $[10,11]$. The first step in the image analysis is recognition of particle images and calculation of image centroids. The next step is to recognize groups of centroids as belonging to an incidence or rebound trajectory. This is achieved using an iterative Kalman filtering algorithm with a likelihood function based on knowledge of the number of particle images along a trajectory. Next, the incidence and rebound trajectories are extrapolated to their intersection points with the glass plate. If the plate intersection points of a pair of incidence and rebound trajectories are close, within an adjustable tolerance, they are assumed to be from the same particle. For this work the tolerance was set at two particle diameters. This tight tolerance restricts the data to particles with instantaneous contacts with the plate; particles that slide or roll upon contact are automatically excluded. Figure 4 shows an example of visible sliding upon contact. This behavior appears to happen only with a small fraction of the glass particles that are non-spherical. The last step in the analysis process involves calculation of angles, velocities and restitution coefficients. This information was extracted based on the displacement of the first and fifth images closest to the wall. Therefore, the measurements presented here are obtained within a $1 \mathrm{~mm}$ region next to the wall. The entire image acquisition and analysis process takes on the order of one second per picture. This enables rapid analysis of thousands of 


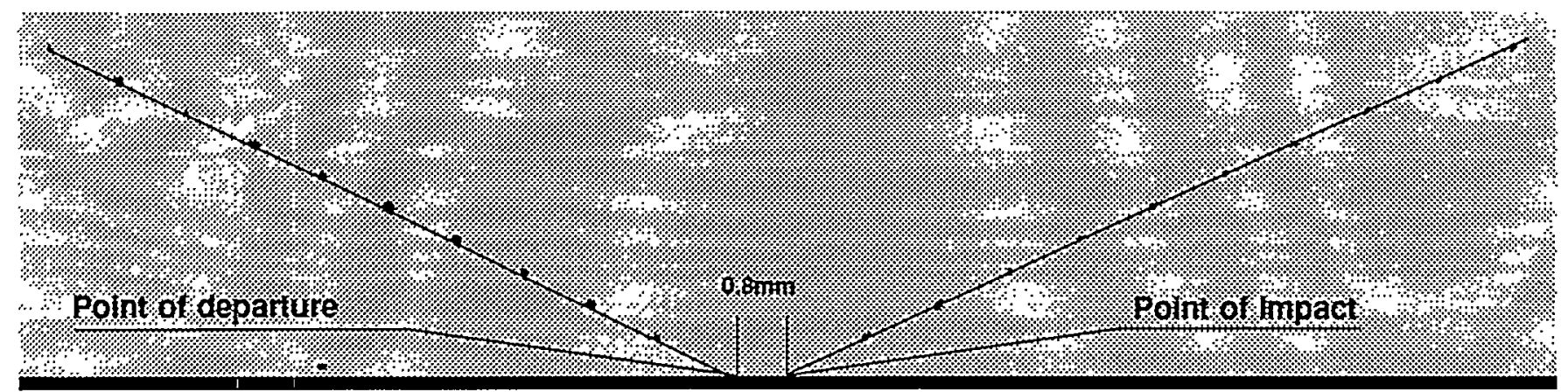

Figure 4. Picture of a particle collision involving visible sliding.

The experimental uncertainties in collision parameters (velocity, angle, and restitution coefficients) arise from two factors: uncertainties in the basic measurements of distance with the imaging system and uncertainties in the timing of laser pulses. The digital pulse generator used in this experiment has one nanosecond resolution making the timing uncertainty negligible. The uncertainty in distance is mainly due to the pixel resolution of the imaging system and the resolution of the scale used to calibrate the imaging system. For this PTV system and experimental conditions, the total uncertainty in distance measurement is $\pm 35 \mu \mathrm{m}$. This translates into an uncertainty of $\pm 0.22 \mathrm{~m} / \mathrm{s}$ in velocity, $\pm 0.6^{\circ}$ in angle, $\pm 5 \%$ in normal restitution coefficient and $\pm 2 \%$ in tangential coefficient of restitution.

\section{RESULTS AND DISCUSSION}

Figures 5 - 8 show the dependence of the tangential and normal coefficient of restitution ( $\beta$ and e, respectively) on incidence velocities, $v_{\mathbf{i}}$, and incidence angle, $\phi_{\mathbf{i}}$. Values for the mean, standard deviation and experimental uncertainties for all measured and calculated parameters are given below in Table 1.

Figure 9 shows the data in terms of a non-dimensional incidence angle, $\Psi_{1}$, and a non-dimensional rebound angle, $\Psi_{2}$, proposed by Maw, Barber and Fawcett $[11,12]$ and defined as

$$
\Psi_{1}=\frac{2(1-v)}{\mu(2-v)} \frac{V_{i, r}}{V_{i, n}} \quad \text { and } \quad \Psi_{2}=\frac{2(1-v)}{\mu(2-v)} \frac{V_{r, t}}{V_{i, n}}
$$

\begin{tabular}{|l|l|c|c|}
\hline & mean & standard deviation & uncertainty \\
\hline Rebound velocity, $\mathrm{v}_{\mathrm{r}},(\mathrm{m} / \mathrm{s})$ & 16.10 & 1.21 & 0.22 \\
\hline Impact velocity, $\mathrm{v}_{\mathrm{i}},(\mathrm{m} / \mathrm{s})$ & 17.07 & 1.29 & 0.22 \\
\hline & & & \\
\hline Rebound angle, $\phi_{\mathrm{r}^{\prime}}\left({ }^{\circ}\right)$ & $17.94^{\circ}$ & $1.84^{\circ}$ & $0.6^{\circ}$ \\
\hline Impact angle, $\phi_{\mathrm{r}^{\circ}}\left({ }^{\circ}\right)$ & $17.5^{\circ}$ & $1.25^{\circ}$ & $0.6^{\circ}$ \\
\hline & & & \\
\hline Normal coefficient of restitution, $\mathrm{e}$ & 0.94 & 0.02 & 0.018 \\
\hline Tangential coefficient of restitution, $\beta$ & 0.97 & 0.07 & 0.05 \\
\hline & & & \\
\hline Coefficient of friction, $\mu$ & 0.027 & 0.009 & \\
\hline
\end{tabular}




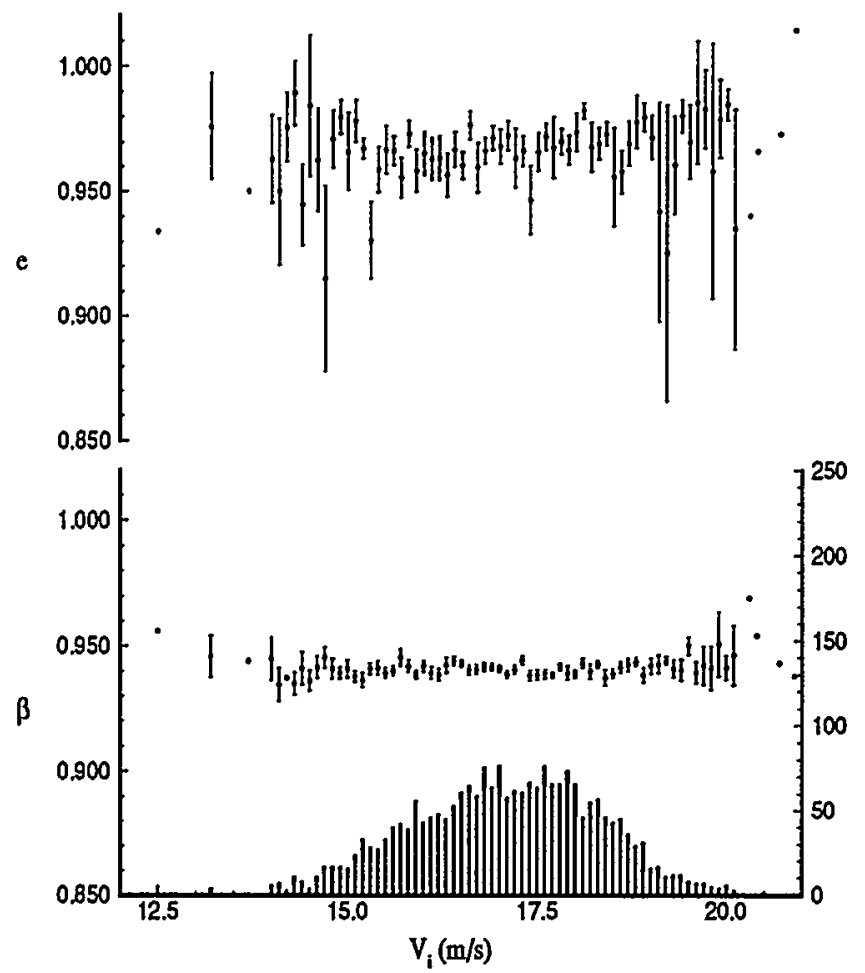

Figure 5. Normal and tangential coefficient of restitution versus incidence velocity. Vertical bars show $95 \%$ confidence intervals.

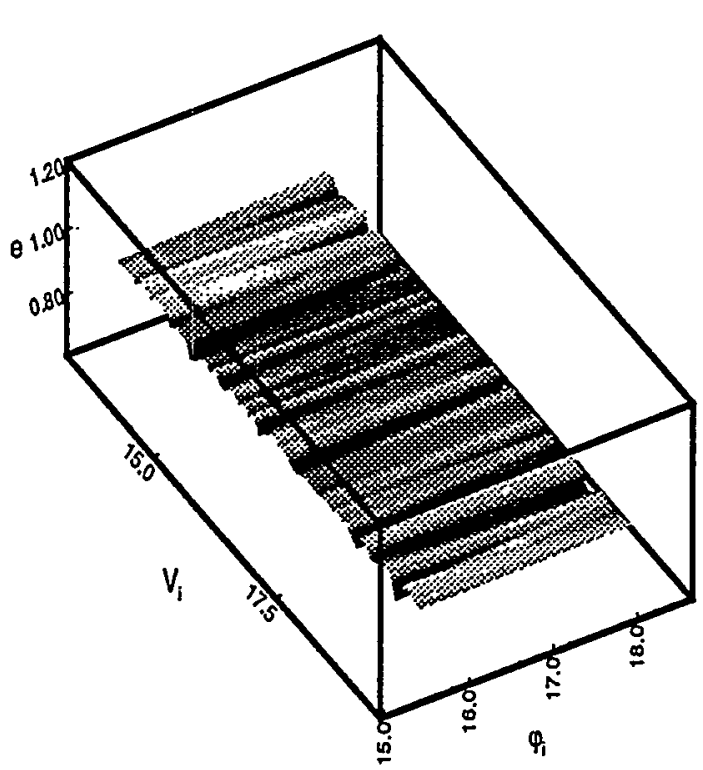

Figure 7. Normal coefficient of restitution versus incidence velocity and incidence angle.
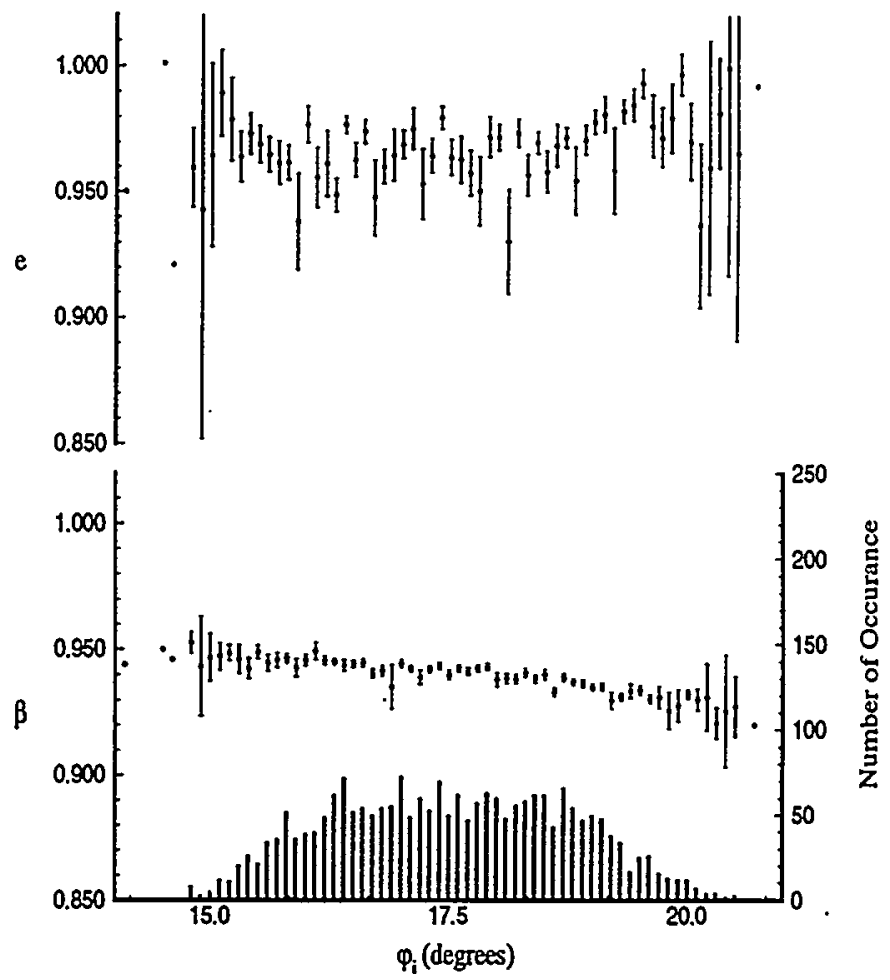

Figure 6. Normal and tangential coefficient of restitution versus incidence angle. Vertical bars show $95 \%$ confidence intervals.

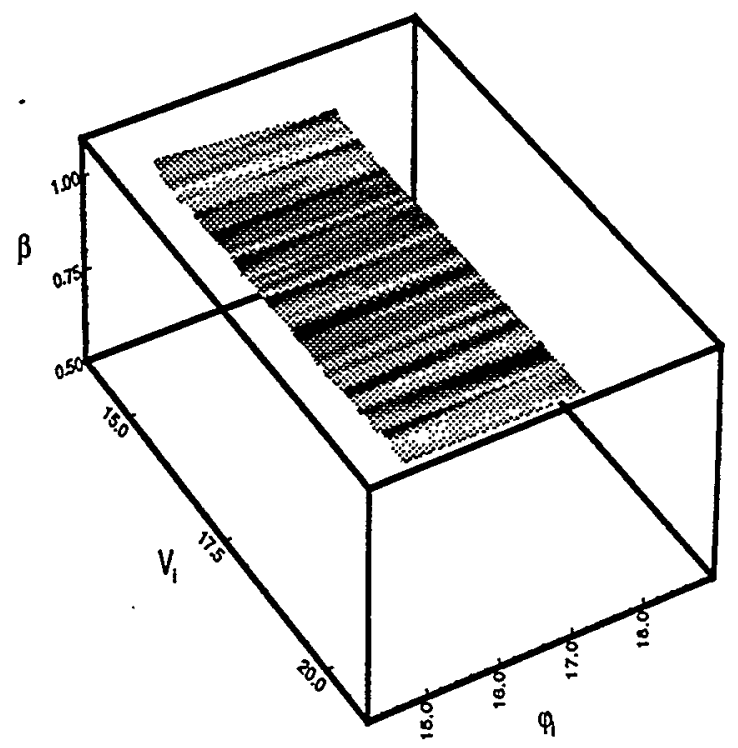

Figure 8. Tangential coefficient of restitution versus incidence velocity and incidence angle. 


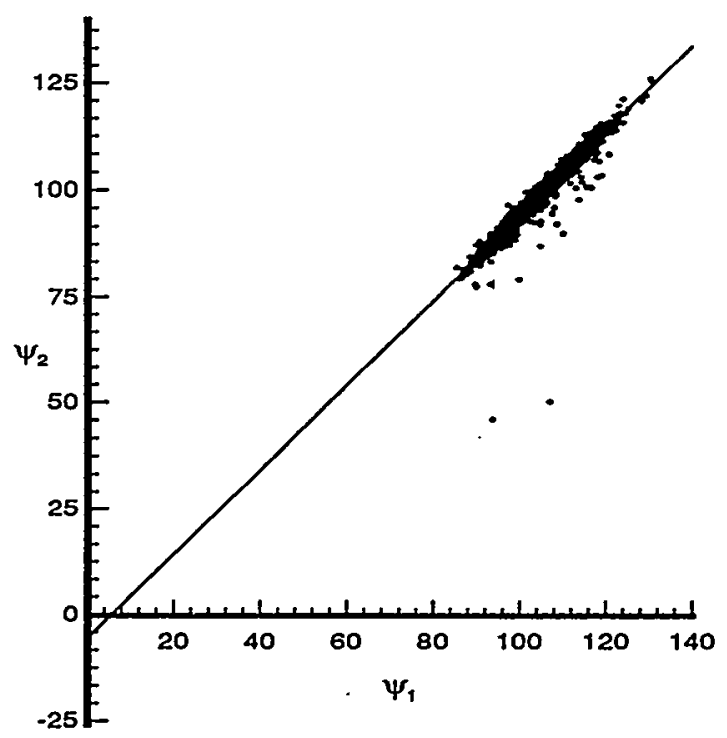

Figure 9. Non-dimenslonal incidence angle versus non-dimensional rebound angle.
In these equations, $v$ is Poisson's ratio, which is 0.22 for glass beads, $V_{i, t}$ is the incidence tangential velocity, $V_{r, t}$ is the rebound tangential velocity, $V_{i, n}$ is the incidence normal velocity, $V_{r, n}$ is the rebound normal velocity, and $\mu$ is a coefficient of friction for collisions. To calculate the coefficient of friction, $\mu$, the following equation is used:

$$
\mu=\frac{V_{i, t}-V_{r, t}}{(1+e) V_{i, n}\left(1+1 / k^{2}\right)}
$$

This equation is valid for the slip regime $[11,12]$ where $\Psi_{1}>4 \chi$. For this experiment, $\chi=0.153$, where $\chi$ is a non-dimensional parameter given by,

$$
\chi=\frac{(1-v)\left(1+1 / k^{2}\right)}{2-v}
$$

with $\mathrm{k}^{2}$ being the radius of gyration which is $2 / 5$ for homogeneous spheres. Using the equations above gives a mean value of 0.027 for $\mu$ with a standard deviation of 0.009 .

The values in Table 1 and the data in Figures 5-9 show that, within the narrow range of incidence angles and velocities for this experiment, $e$ and $\beta$ are independent of $\phi_{i}$ and $v_{i}$. Data presented in Goldsmith [3] show that $e$ varies with $v_{i}$ only for low velocities, $v_{i}<1 \mathrm{~m} / \mathrm{s}$, where e decreases with $v_{i}$. It is also obvious that the collisions are specular, as expected for spherical glass particles colliding with a smooth glass plate.

This experimental system is now being used with particles and wall materials of industrial significance. Eventually a data bank will be produced for a wide range of particle types, wall materials and flow conditions.

\section{ACKNOWLEDGMENTS}

This work was done under Cooperative Research and Development Agreement No. PC93-006 between the U.S. Department of Energy and Carnegie Mellon University (CMU). The authors from CMU wish to gratefully acknowledge funding from the Amoco Oil Company. The important contributions of Bala Kumar of the CMU Robotics Institute and R. Srinivasan of EASI Inc. with image analysis are also acknowledged. 


\section{REFERENCES}

1. Yasuna, J., Bolio, E., Gamwo, I. and J. Sinclair, AIChE Symposium Series, 89 (1993) 184.

2. Louge, M., Mastorakos, E., and J. Jenkins, J. Fluid Mech., 231 (1991) 345.

3. Goldsmith, W. "Impact - The Theory and Behavior of Colliding Solids", Edward Arnold Publishers, London (1960).

4. Tabakoff, W. and Malak, M.F., "Laser Measurement of Fly Ash Rebound Parameters for Use in Trajectory Calculations," J. Turbomachinary, Vol. 109, Oct. 1987.

5. Foerster, S., Louge, M., Chang, H. and Allia, K. , Physics of Fluids A, submitted for publication.

6. Shaffer, F.D., Ekmann, J.M., and Ramer, E.R., "Development of Pulsed-Laser Velocimetry Systems Utilizing Photoelectric Image Sensors," Proc. of the AIAA/ASME/SIAM/APS First National Fluid Dynamics Congress, Cincinnati, OH, July 1988.

7. Shaffer, $\mathrm{F}$ and Ramer, E., "Pulsed Laser Imaging of Particle-Wall Collisions", in Proceedings of the International Conference on the Mechanics of Two-Phase Flow, 12-15 June 1989, Taipai, Taiwan (1989) 116.

8. Sommerfeld, M. "Application of Optical Non-Intrusive Measurement Techniques for Studies of GasSolid Flows," ASME Fluids Engineering Meeting, Gas-Solid Flow Symposium, June 1993.

9. Sondergaard, R., Chaney, K. and C. Brennen, ASME J. of Applied Mechanics, 57 (1990) 694.

10. Ramer, E. and F. Shaffer, Applied Optics, 31 (1990) 779.

11. Singh, R., Shaffer, F., and Borovetz, H., "Fluorescent Image Tracking Velocimetry Algorithms for Quantitative Flow Analysis in Artificial Organs," Int. Symp. on Electronic Imaging, San Jose, CA, January 1993.

12. Maw, N., Barbar, J.R., and Fawcett, J.N., "The Oblique Impact of Elastic Spheres," Wear, 38(1), 101114, 1976.

13. Maw, N., Barbar, J.R., and Fawcett, J.N., "The Role of Elastic Tangential Compliance in Oblique Impact," ASME J. of Lubrication Technology, 103, 74-78, 1981. 


\title{
A COMPARATIVE APPLICATION OF A PARTICLE TRACKING VELOCIMETRY AND LASER DOPPLER VELOCIMETRY FOR PARTICLE-WALL COLLISION MEASUREMENTS
}

\author{
Heshmat Massah \\ Chemical Engineering Department \\ Camegie Mellon University \\ Pittsburgh, PA 15129 \\ Mohrdad Shahnam \\ Gilbert Commonwealth \\ Library, PA 15236 \\ Franklin Shatfer \\ Pittsburgh Energy Technology Center \\ US Department of Energy, \\ Pittsburgh, PA 15236 \\ Jennifor Sinclair \\ Chemical Engineering Department \\ Camegie Mellon University \\ Pittsburgh, PA 15129
}

\begin{abstract}
The properties of particle-wall collisions measured using a particle tracking velocimetry (PTV) system and a laser Doppler velocimeter (LDV) are compared. The measured parameters are rebound angles and velocities and approach angles and velocities. From these measured parameters, normal coefficients of restitution $(c)$, the ratio of the tangential approach to tangential rebound velocities $(\beta)$ and the ratio of rebound to approach angle $\left(\varphi_{\mathrm{r}} / \varphi_{\mathrm{a}}\right)$ are derived. In this study, $191 \mu \mathrm{m}$ spherical glass particles were collided with a smooth glass plate with a narrow range of approach angle around a mean value of $50^{\circ}$ (with respect to the glass plate) and with a narrow range of approach velocity around a mean value of about $18 \mathrm{~m} / \mathrm{s}$. Despite differences in the way $\varphi_{z} / \varphi_{a}, e$, and $\beta$ are calculated for LDV and PTV, both PTV and LDV measurements led to almost identical resuits. The expecimental uncertainty in velocity for both techniques was less than three percent.
\end{abstract}

\section{NOMENCLATURE}

V Velocity vector $(\mathrm{m} / \mathrm{s})$

u Axial component of velocity (m/s)

$v$ normal component of velocity $(\mathrm{m} / \mathrm{s})$

$\beta$ The ratio of the tangential approach to the tangential rebound velocities

e Normal coefficient of restitution

$\varphi_{i} \quad$ Approseh angle (degree)

Pr Rebound angle (degree)

\section{INTRODUCTION}

Particle-wall collisions are encountered in many industrial systems such as particle deposition in combustion systems, erosion of turbine blades in jet engines by airbome particulate, fluidization for chemical processing, and the pneumatic transport of particles from one location to another.

To predict the behavior of particulate flow systems using either Lagrangian or Eulerian models, one needs to understand the physics of collisions between particles and the boundary walls and between particles themselves. Specifically, the changes in the tangential and the normal components of velocity upon collision are needed.

Tabakoff and Malak (1987) have used laser Doppler velocimetry (LDV) to measure the collisional properties of fly ash impacting differeat plates made of ahuminum, titanium and stainless steel.

Massah et al. $(1994,1995)$ used a PTV system developed by Shaffer et al. (1988) to track individual particles and to measure their velocities before and after collision with a wall. Sommerfeld (1993) used a similar PTV system to measure large quantities of particle-wall collisions to characterize diffuse scattering by a rough surface.

The purpose of this study is to compare LDV and PTV measurements of glass spheres colliding with a glass plate. The parameters measured include time-averaged approach angle and velocity and time-averaged rebound angle and velocity. Of particular interest are the restiution coefficients calculated from these measured parameters. 


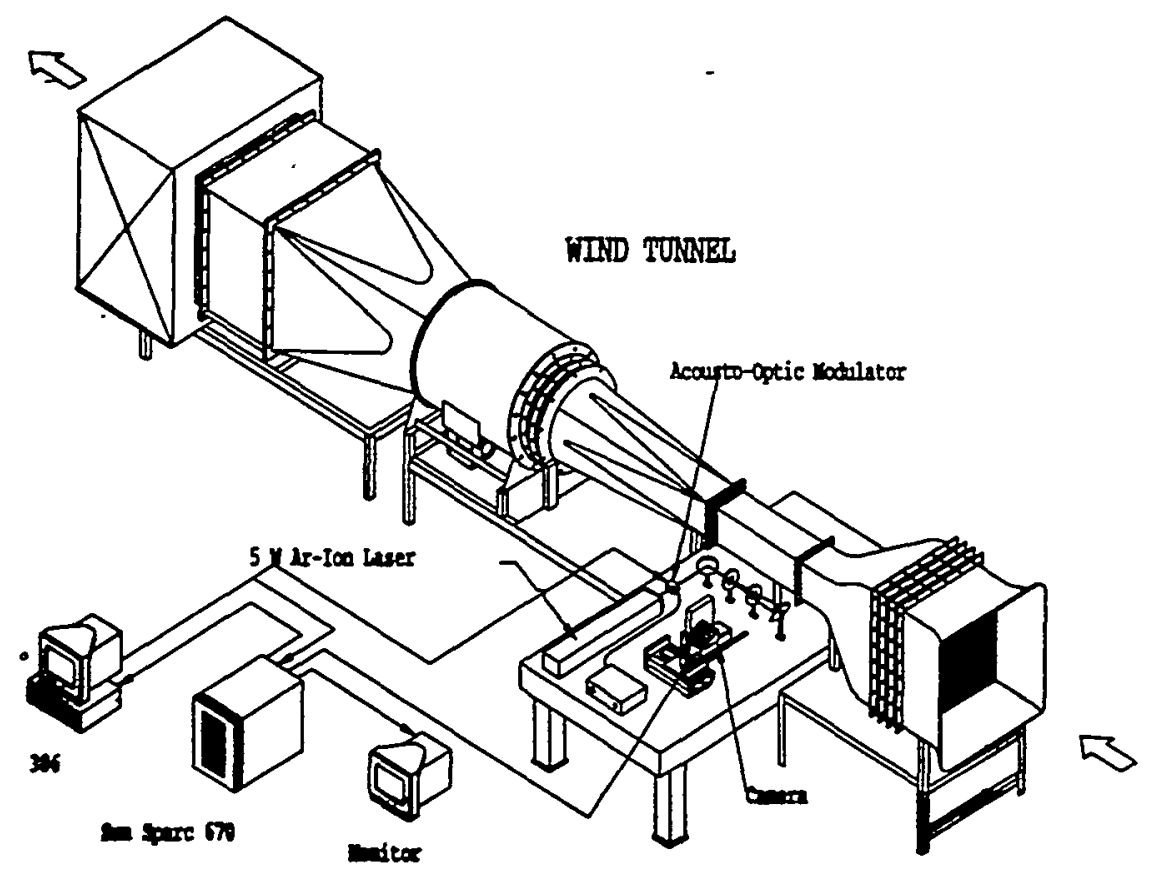

FIGURE 1. SCHEMATICS OF EXPERIMENTAL SETUP

The glass particles were sieved to a size range of 175-208 $\mu \mathrm{m}$ and the glass plate is a piece of smooth glass sheet, $3 \mathrm{~mm}$ thick. Only spherical particles with a sphericity of $95 \%$ or higher were used. The particles are injected at a mean angle of $50^{\circ}$ with respect to the glass plate and a mean velocity of $18 \mathrm{~m} / \mathrm{s}$. The range of approach angle and approach velocity was kept narrow with a standard deviation of $4^{\circ}$ and $3 \mathrm{~m} / \mathrm{s}$, respectively.

\section{EXPERIMENTAL SETUP}

The experimental system originally designed by Shaffer et al. (1989) was used in this study. It is located in the Flow Analysis Facility of the Department of Exergy's Pittsburgh Energy Technology Center. Figure 1 shows the configuration of the experimental equipment (the feeding system is not shown). In the test section of the wind wunel, glass particles are brought into collision at the center of a smooth glass plate under accurately controlled conditions. The particles are driven by poeumatic transport through a $4 \mathrm{~mm}$ tube. The exit of the injection tube is placed about $2 \mathrm{~cm}$ above the glass plate and is tilted downward to an angle of about $50^{\circ}$ with respect to the gless plate. Particles are fed into the pneumatic transport line at a steady rate. The effect of drag on measured properties was minimized by using a wind tunnel sweep velocity of $4 \mathrm{~m} / \mathrm{s}$.
The glass particles have a material density of $2.47 \mathrm{~g} / \mathrm{cm}^{3}$ and a diameter distribution of 175 to $208 \mu \mathrm{m}$ with a mean of $191 \mu \mathrm{m}$ The glass particles are searly perfect spheres; aspherical particles are removed using a proprietary technique under development at PETC.

The dimensions of the glass plate were $27 \mathrm{~cm} \times 27 \mathrm{~cm}$ with a thickness of $3 \mathrm{~mm}$. Support posts were placed at the corners of the plate. The size of the plate and the distance of the support posts from the collision point were sufficient to ensure that the collisions are independent of the finite plate dimensions. This was verified based on the criteria given by Sondergaand et al. (1990).

\section{A. PTV measuagnents}

The beam from an acousto-optically modulated, TW argon laser is transmitted through a series of cylindrical lenses forming a thin (1 mm) sheet of pulsed laser light. The sheet was directed parallel to the flow upward through and normal to the glass plate. The laser sheet was pulsed at a rate of $25 \mathrm{KHz}$, with pulce duration of $5 \mu \mathrm{s}$.

As particles pass through the light sheet, they scatter light into a high-resolution (1024 $\times 1024$ pixel) video camera positioned with its line-of-view normal to the laser sheet. This proctuces a multipleexposure picture showing a series of images of a particle along its 
trajectory. By measuring the distance between images and knowing the time between laser pulses, a velocity vector was derived. To minimize the uncertainty associated with the distance, the distance was measured between the first image and the fifth image closest to the wall. The field-of-view size was $34.69 \times 26.92 \mathrm{~mm}$.

The PTV pictures are digitized at 30 pictures/second with 8-bit (255 levels) gray-scale resolution into a SUN 670 computer with an ANDROX parallel image processor. Only a $3.42 \mathrm{~mm}$ region of the PTV picture near the wall is stored permanently. Particle images are detectable within one particle image diameter of the plate surface.

Lighting conditions were set so that the raw digital pictures have a uniform background gray-level. This was accomplished by increasing the camera black-level above the background level. With a uniform background, the image compression efficiency is more than 95\%; this is necessary to economically store thousands of images.

Software has been developed at PETC to automatically analyze multiple-exposure pictures of particle trajectories (Ramer and Shaffer, 1990, and Singh et al , 1993). The first step in the image analysis is recognition of particle images and calculation of image centroids. The next step is to recognize groups of centroids as belonging to an approach or rebound trajectory. This is achieved using an iterative Kalman filtering algorithm with a likelihood function based on apriori knowledge of the number of particle images along a trajectory. Next, the approach and. rebound trajectories are extrapolated to their intersection points with the glass plate. If the intersection points of a pair of approach and rebound trajectories with the plate are close, within an adjustable tolerance, they are assumed to be from the same particle. For this work the tolerance was set at two particle image diameters. This tight tolerance restricts the data to particles with instantaneous contacts with the plate; particles that slide or roll upon contact are automatically excluded. The last step in the analysis process involves calculation of angles, velocities and restitution coefficients. The angles and velocities were calculated using the first and fifth image closest to the wall of a trajectory. This fails within a $1.5 \mathrm{~mm}$ region sext to the wall. The entire image acquisition, analysis and storage process takes about one second per picture. This enables rapid analysis of the thousands of trajectories required for statistical convergence.

\section{B. LDV MEASURENENTS}

A two-component, fiber-optic LDV was used to measure the approach and rebound velocity components of the glass particles colliding with the glass plate. The LDV system consists of a Spectra-Physics argon laser (5W), a TSI Colorburst model 9201 coupled to a two-component, fiber-optic transmitting/receiving probe and a DANTEC 58N10 PDA signal processor. The LDV probe was placed where the camera is shown in Figure 1 . The rest of the experimental setup remained as shown in Figure 1. Data ecquisition was controlled via a 80486-DX2 computer. Table 1 lists the LDV characteristics.

To place the LDV measuring volume very close to the glass plate, the LDV probe was rotated $45^{\circ}$ about its line-of-view and tilted downward about $3^{\circ}$ so that two of the four beams were almost parallel to the glass plate. Figure $2 a$ shows a schematic drawing of the fringes in the measurement volume created by the blue and green beams. Figures $2 \mathrm{~b}$ and $2 c$ show the fringes created by the blue and green beams alone. They are perpendicular to each other and at a $45^{\circ}$ angle to the plate. In Figure 2, U1 and U2 are components of the velocity measured by the bhe and the green beams, respectively. The normal component $(v)$ and the tangential component (u) of the velocity in the "plate" coordinate system were calculated from equations (1) and (2).

$$
\begin{aligned}
& v=-U 1 \times \operatorname{Cos}\left(45^{\circ}\right)+U 2 \times \operatorname{SIN}\left(45^{\circ}\right) \\
& u=U 1 \times \operatorname{SIN}\left(45^{\circ}\right)+U 2 \times \operatorname{COS}\left(45^{\circ}\right)
\end{aligned}
$$

\section{TABLE 1. LDV PARAMETERS}

\begin{tabular}{|l|l|l|}
\hline Color & Green & Blue \\
\hline Wavelength $(\mu \mathrm{m})$ & 514.5 & 488 \\
\hline $\begin{array}{l}\text { Front lens focal } \\
\text { length (mm) }\end{array}$ & 350 & 350 \\
\hline Fringe spacing $(\mu \mathrm{m})$ & 3.611 & 3.425 \\
\hline $\begin{array}{l}\text { Measuring volume } \\
\text { diameter }(\mu \mathrm{m})\end{array}$ & 163 & 160 \\
\hline $\begin{array}{l}\text { Measuring volume } \\
\text { length (mm) }\end{array}$ & 2.28 & 2.24 \\
\hline $\begin{array}{l}\text { Number of stationary } \\
\text { fringes }\end{array}$ & 45 & 47 \\
\hline
\end{tabular}

(c)

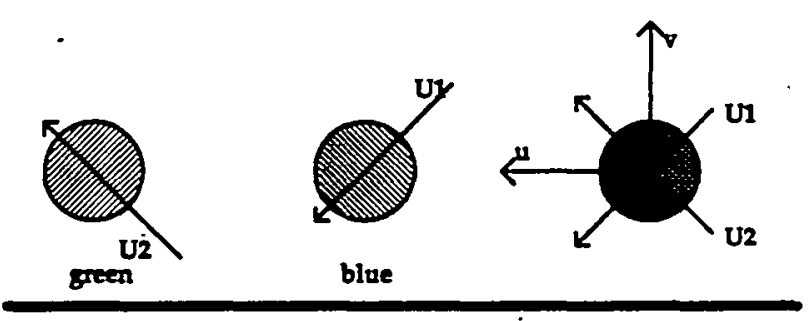

\section{FIGURE 2. DIRECTION OF FRINGES IN THE LDV MEASUREMENT VOLUME}

Care was taken to ensure that LDV measurements covered the same vohume over which PTV measurements were made. The LDV measurement volume was placed about $2 \mathrm{~mm}$ above the plate at a location where PTV measurements were done. PTV results are based on images within $2.5 \mathrm{~mm}$ above the plate and along a 5 mm length of the plate. Therefore, LDV measurements were taken at five points, $1 \mathrm{~mm}$ apart, over the same $5 \mathrm{~mm}$ length, as shown in Figure 3. Three thousand samples were taken af each point with LDV. The data from all five points was then combined. 


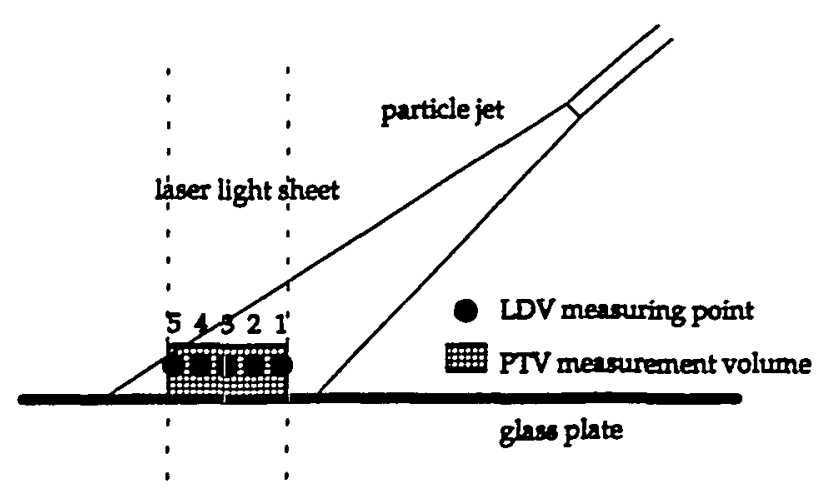

FIGURE 3. MEASUREMENT VOLUMES OF PTV AND LDV

Figure 4 shows two typical paths that particles take. Some particles (particle 1) collide with the plate and cross the measurement volume on their rebound path. The vertical component of velocity of these particles has a positive sign. Such data were taken as rebound data (i.e., rebound tangential and normal velocities and angle). Other particles (particle 2) cross the measurement volume on their approach path and then collide with the plate. The vertical component of velocity of these particies has a negative sign. These data were taken as approach data (i.e., approach tangential and normal velocities and angles). The measurements at the middle 3 points (points 2,3 and 4) shown in Figure 3, resulted in almost equal number of approach and rebound data. Point 1 contained mostly approach data and point 5 contained mostly rebound information.

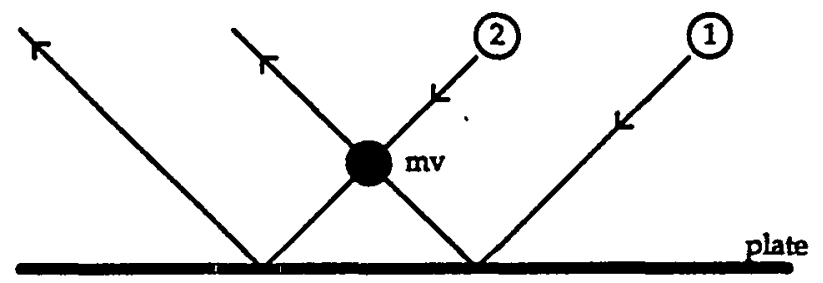

FIGURE 4. TYPICAL PATHS OF PARTICLES IN THE LDV MEASUREMENTS

\section{DISCUSSIONS AND RESULTS}

The experimental uncertainty in PTV measurements arises from two factors: 1) uncertainty in measuring the distance between the centroids of images and, 2) uncertainty in the timing of laser pulses. The digital pulse-generator used in this experiment has nanosecond resolution making the timing uncertainty negligible. The uncertainty in measuring the distance is limited by the pixel resolution of the imaging system and the resolution of the scale used to calibrate the imaging system. For the experimental conditions of this study, the average uncertainty in measuring the mean tangential component of velocity is $0.30 \mathrm{~m} / \mathrm{s}$ and that for the mean normal velocity is $0.23 \mathrm{~m} / \mathrm{s}$.

The uncertainty in LDV measurements is mostly due to limitations in the resolution of the frequency bandwidth of the signal processor. The uncertainty in measuring both the mean tangential component of velocity and the mean normal component of velocity is $0.155 \mathrm{~m} / \mathrm{s}$.

TABLE 2. PTV AND LDV MEASUREMENTS IN THE PARTICLE JET

\begin{tabular}{|cc|c|c|}
\hline & PTV & LDV \\
\hline $\mathrm{V}$ & $\mathrm{m} / \mathrm{s}$ & $18.97 \pm 0.37$ & $18.84 \pm 0.16$ \\
\hline $\mathrm{u}$ & $\mathrm{m} / \mathrm{s}$ & $11.18 \pm 0.30$ & $11.36 \pm 0.16$ \\
\hline $\mathrm{v}$ & $\mathrm{m} / \mathrm{s}$ & $15.27 \pm 0.23$ & $14.98 \pm 0.16$ \\
\hline $\mathrm{e}$ & degrees & $53.90 \pm 1.97$ & $53.20 \pm 1.20$ \\
\hline
\end{tabular}

To verify the performance of both LDV and PTV, measurements were done with the plate removed. The rest of the experimental conditions were as described earlier. Table 2 shows that the values measured for the jet were the same within experimental uncertainty. The histograms of velocity and angle are shown in Figures 5 \& 6 .
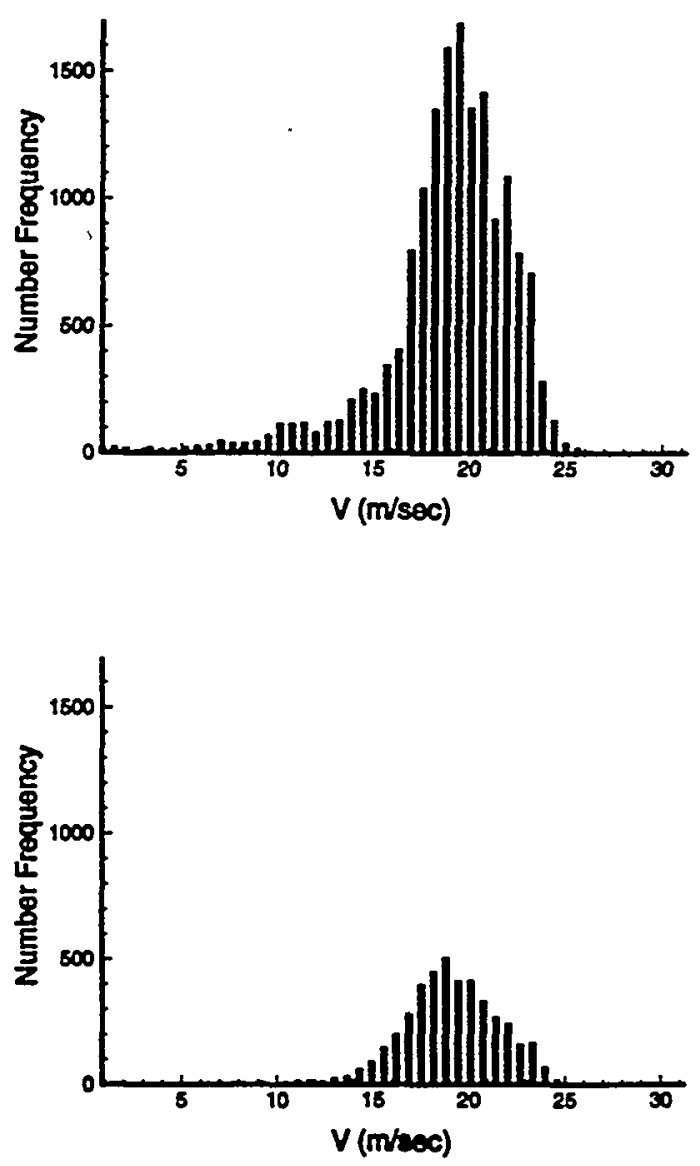

FIGURE 5. HISTOGRAMS OF VELOCITIES MEASURED FOR JET BY LDV (TOP) AND PTV (BOTTOM) 

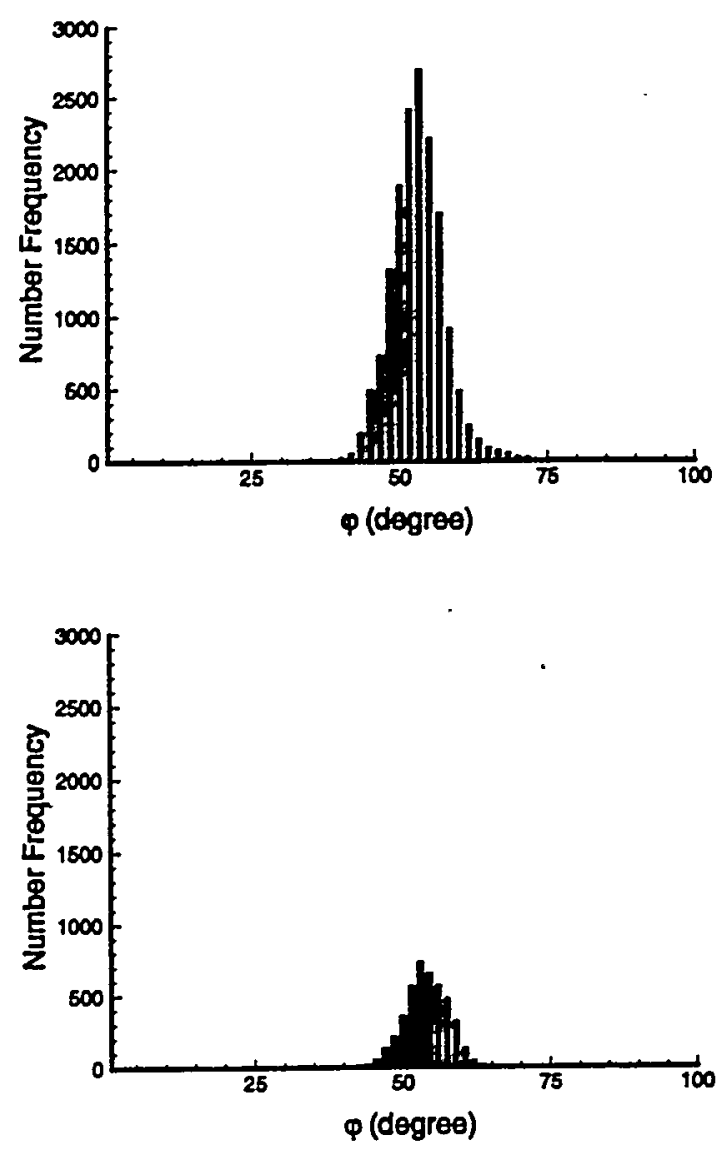

FIGURE 6. HISTOGRAMS OF ANGLES OF TRAJECTORIES MEASURED FOR JET BY LDV (TOP) AND BY PTV (BOTTOM)

Particle wall collision properties are often expressed in terms of $e, \beta$ and the ratio of rebound to approach angle $\left(\varphi_{r} / \varphi_{a}\right)$. Table 3 shows that these nondimensional parameters obtained by PTV and LDV are in good agreement.

TABLE 3. COLUSION PARAMETERS MEASURED BY PTV AND LDV

\begin{tabular}{|c|c|c|}
\hline & PTV & LDV \\
\hline$q_{R} Q_{2}$ & $1.11 \pm 0.08$ & $1.12 \pm 0.03$ \\
\hline$e$ & $0.95 \pm 0.03$ & $0.95 \pm 0.02$ \\
\hline$\beta$ & $0.75 \pm 0.05$ & $0.76 \pm 0.02$ \\
\hline
\end{tabular}

The number of data taken with LDV is about 15000 while the number of data taken by PTV is about 1500 . A tristical analysis of the data showed that 1000 data were sufficient for convergence of both mean and standard deviation values.
The normal restitution coefficient and tangential velocity ratio are given by:

$$
\begin{array}{ll}
e=\frac{v_{r}}{v_{a}} & \text { normal coefficient of restitution } \\
\beta=\frac{u_{r}}{u_{a}} & \text { tangential velocity ratio. }
\end{array}
$$

Therefore the normal restitution coefficient and the tangential velocity ratio of a sample with $\mathrm{N}$ collisions is

$$
\begin{aligned}
& \bar{e}=\sum_{m=1}^{N} e_{m}=\sum_{m=1}^{N}\left[\frac{v_{r}}{v_{a}}\right]_{m} \\
& \bar{\beta}=\sum_{m=1}^{N} \beta_{m}=\sum_{m=1}^{N}\left[\frac{u_{r}}{u_{a}}\right]_{m}
\end{aligned}
$$

However, we to inability of LDV to follow the same particle before and after a collision, the values of $e$ and $\beta$ are calculated using the mean rebound and approach particle velocities as:

$$
\bar{e}=\frac{\bar{v}_{r}}{\bar{v}_{a}}=\frac{\sum_{m=1}^{N}\left[v_{r}\right]_{m}}{\sum_{m=1}^{N}\left[v_{a}\right]_{m}}
$$

$\bar{\beta}=\frac{\bar{u}_{r}}{\bar{u}_{a}}=\frac{\sum_{m=1}^{N}\left[u_{r}\right]_{m}}{\sum_{m=1}^{N}\left[u_{a}\right]_{m}}$

Even though equations (1) and (2) are different than equations (3) and (4), the results of LDV and PTV measurements are in good agreement. This indicates that LDV and PTV provide the same results for collisions where the variations in approach and rebound velocities and angles are small. Work is underway to extend the present study to diffuse particle collisions and to investigate the possible effect of approsch angle and velocity on the collisional parameters.

\section{ACKNOWLEDGMENTS}

This wot was done under Cooperative Research and Development Agreement No. PC93-006 between the U.S. Department of Energy and Carnegie Mellon University (CMU). The authors from CMU wish to gratefully acknowledge funding from the Amoco Oil Company. The important contributions of Bala Kumar of the CMU Robotics Institute and R. Srinivasan of EASI Inc. with image analysis are also acknowledged. 


\section{REFERENCES}

Tabakoff, W., and Malak, M.F., Oct. 1987, "Laser Measurement of Fly Ash Rebound Parameters for Use in Trajectory Calculations", Lof Tutbomechinary, Vol. 109.

Massah, H., Shaffer, F.D., Sinclair, J., Shahnam, M., November 1994, "Non Intrusive Measurements of Perticle-Wall Collision Properties"; Proceedings, Anmual AKCtE Mesting, Sen Francisco, Califonia.

Massah, H., Shaffer, F.D., Sinclair, J., Shahram, M., May 1995 , Measurements of Diffuse and Specular Particle-Wall Collision Properties"; sccepted for publication in Proceedings, International Symposium of the Engineerine Foundation. Fluidization III; Toulouse, France.

Shaffer, F.D., Elmann, J.M., and Ramer, E.R. , July 1988, "Development of Pulsed-Laser Velocimetry Systems Utilizing Photoelectric Image Sensors," Proceedings, ALANASME/SLAM/APS First National Fluid Dynamics Conoress, Cincinnati, $\mathrm{OH}$.

Sommerfeld, M. , June 1993, "Application of Optical NonIntrusive Measurement Techniques for Studies of Gas-Solid Flows," ASME, Fluids Enoineerine Meting, Gas-Solid Flow Symposium.

Shaffer, F.D. and Ramer, E., June 1989, "Pulsed Laser Imaging of Particle-Wall Collisions", in Proceedings of the International Conference on the Mechanics of Two-Phase Flow, Taipai, Taiwan , Vol 116, pp. 12-15.

Sondergaard, R., Chaney K. and Brennen C., 1990, ASMEJ. of Applied Mechanics, Vol 57, p. 694.

Ramer, E. and Shaffer, F.D., 1990, Applied Optics, Vol 31, p. 779.

Singh, R., Shaffer, F.D., and Borovetz, H., January 1993, Fiuorescent Image Tracking Velocimetry Algorithms for Quantitative Flow Anslysis in Artificial Organs." Int. Symo, en Electrosic Imaging, San Jose, CA. 


\title{
MEASUREMENTS OF SPECULAR AND DIFFUSE PARTICLE-WALL COLLISION PROPERTIES
}

\author{
Heshmat Massah ${ }^{1}$, Franklin Shaffer ${ }^{2}$. Jennifer Sinclair ${ }^{1}$ and Mehrdad Shahnam ${ }^{3}$
}

1. Department of Chemical Engineering, Carnegie Mellon University, Pittsburgh, PA 15213

2. U.S. Department of Energy, Mail Stop 84-340, P.O. Box 10940, Pittsburgh, PA 15236

3. Gilbert Commonwealth, Inc., Library, PA 15129

\section{SUMMARY}

This paper describes the measurement of specular and diffuse particle-wall collisions using a particle image tracking velocimetry (PTV) system. The PTV system tracks an individual particle before and after a collision and is capable of measuring thousands of particlewall collisions per hour. The measured parameters are approach and rebound angles and velocities for a specific particle. From these measured parameters, the normal and tangential coefficients of restitution and the coefficient of collisional friction are derived. In this work. specular collisions were produced with $191 \mu \mathrm{m}$ glass particles colliding with a glass plate and diffuse collisions were produced with $90 \mu \mathrm{m}$ FCC particles colliding with a rough riser wall. The approach angles were about $15^{\circ}$ and approach velocities about $20 \mathrm{~m} / \mathrm{s}$. For the glass particles, standard deviations of $7.4 \%$ and $2.1 \%$ were found for the normal and tangential coefficients of restitution, respectively. The standard deviations were much larger for the FCC particles: $38.2 \%$ and $15.7 \%$ for the normal and tangential coefficients of restitution. respectively.

\section{INTRODUCTION}

Particle-wall collisions play an important role in many industrial systems. Some examples are particle deposition in combustion systems, material coating processes. erosion of turbine blades in jet engines by airbome particulates. fluidization for chemical processing, and the pneumatic transport of particles from one location to another.

Computer simulation of particulate flows is a powerful design tool for these systems. Whether the computer simulations track individual particles or treat the particle phase as a continuum, the manner in which the collisions are described greatly influences the flow predictions $(1,2)$. The goal of this project is to provide the empirical data for particle-wall collisions needed to enhance the predictions of computer simulations. Required are time-averaged properties of rebound angles and velocities as a function of approach angle and velocity for a wide range of particle and wall materials. 
In the past, descriptions of particle-wall collisions were limited to data for the normal coefficient of restitution, a simple measurement of the ratio of rebound to approach velocities normal to a wall (3). However, in actual industrial systems, particle-wall collisions are much more complex than described by the normal coefficient of restitution. For example, the change in the tangential component of velocity (parallel to the wall) may not be the same as described by the normal coefficient of restitution. Also, for rough walls or aspherical particles, rebound angles and velocities may vary considerably for a given approach velocity and angle, i.e., the rebound scattering is diffuse rather than specular.

Tabakoff et al. (4) used laser Doppler velocimetry (LDV) to make point measurements of two components of particle velocity near a wall. While LDV quickly generates a large quantity of data, it cannot follow the same particle before and after a collision. Unless the approach angle and velocity are confined to a narrow range, LDV does not provide a true measure of the coefficients of restitution. Recently Foerster et al. (5) measured particle trajectories before and after a collision using frame-to-frame video tracking. Their system is capable of releasing particles without spin and is more suitable for large particles $(>1 \mathrm{~mm})$ and low velocities $(<2 \mathrm{~m} / \mathrm{s})$. However, it has yet to produce large numbers of measurements for determination of time-averaged properties. In 1988 and 1989, Shaffer et al. (6,7) described a particle tracking velocimetry (PTV) system for measurement of particle-wall collisions. The PTV technique generates true values of coefficient of restitution since it tracks each specific particle before and after a collision. More recently, Sommerfeld presented measurements of large quantities of particle-wall collisions with rough surfaces using a PTV system (8).

In this paper, we describe an experiment that rapidly measures the particle-wall collision parameters required for input into computer simulations: time-averaged values of rebound angle and velocity as a function of approach angle, approach velocity, particle type, and wall material. The experimental system was developed by Shaffer et al. $(6,7)$ in the Flow Analysis Facility of the Department of Energy's Pittsburgh Energy Technology Center. With the PTV system, a pulsed laser produces a multiple-exposure picture of a particle along its trajectory. By measuring the displacement of successive particle images, the particle trajectory and velocity along a trajectory are determined - including a particle's trajectory before and after collision with a wall. The system is capable of measuring thousands of trajectories in a few hours, allowing determination of time-averaged properties.

Measurements were done for two systems: glass particles colliding with a smooth glass plate and fluid cracking catalyst (FCC) particles colliding with a rough riser wall. The riser wall was a piece of refractory cement from the inside of the riser pipe of a petroleum refining unit; it was supplied by the Amoco Oil Co. The length scales of the roughness of the riser wall surface were both larger and smaller than the FCC particle diameter. The glass particles and the FCC particles were sieved to a range of $175-208 \mu \mathrm{m}$ and $75-105 \mu \mathrm{m}$, respectively.

\section{EXPERIMENTAL PROCEDURE}

Figure 1 shows the configuration of the experimental equipment for the glass on glass system. The particle-wall collisions are set up in a wind tunnel under accurately controlled conditions. In the test section of the wind tunnel, glass particles are brought into collision at the center of the smooth glass plate. The particles are driven by pneumatic transport through a 4 $\mathrm{mm}$ i.d. tube under a constant pressure of $40 \mathrm{psig}$. The injection tube is placed $10 \mathrm{~cm}$ above the glass plate and is tilted downward about $20^{\circ}$. Particles are fed into the pneumatic transport line at a steady rate using a feed regulator and a screwfeeder in series. Since the laser light cannot 

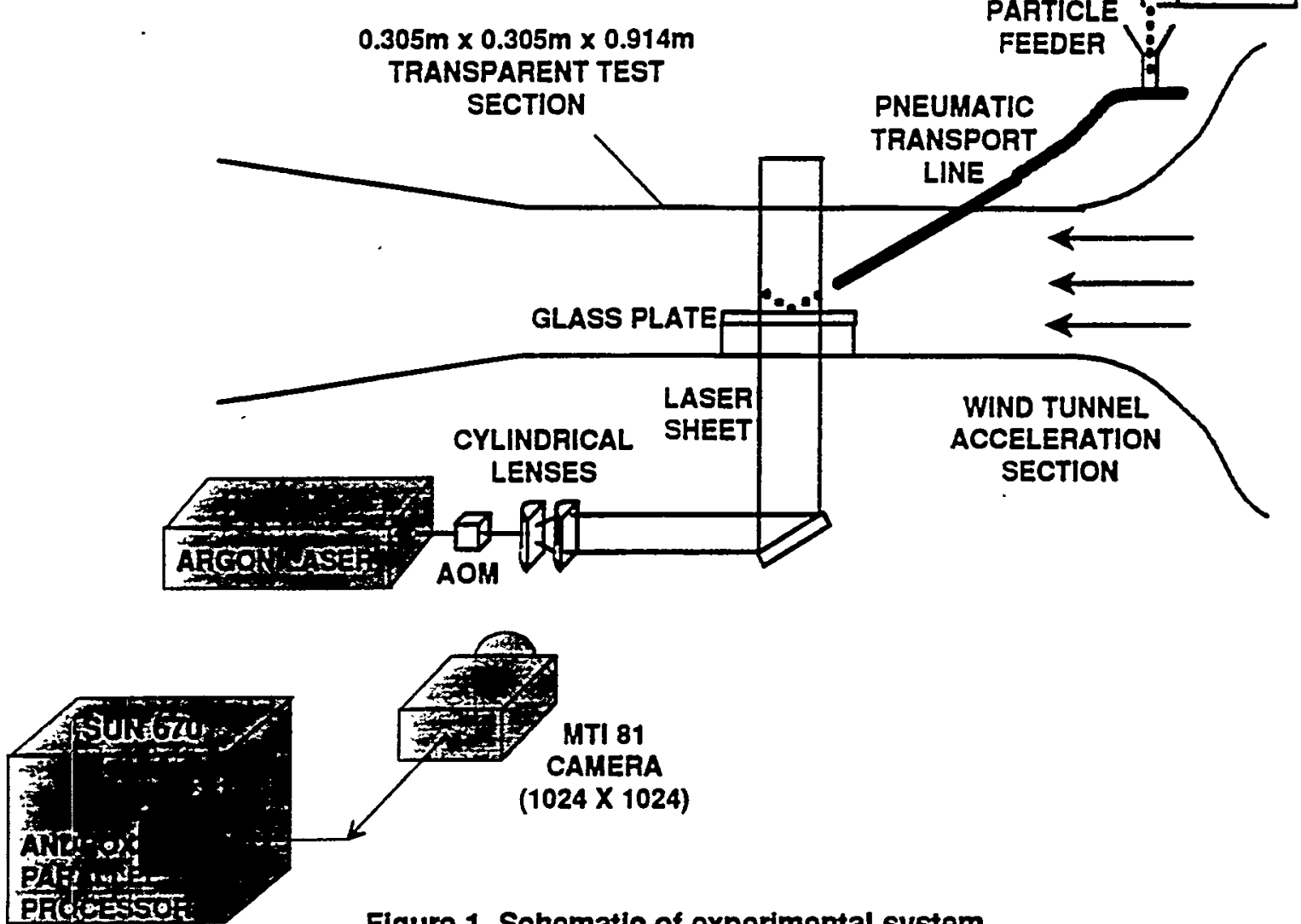

Figure 1. Schematic of experimental system.

pass through refractory cement, for the FCC-riser wall system, the riser wall was mounted facedown on the ceiling of the wind tunnel test section and the injection tube was tilted upward.

The glass particles have a mean size of $191 \mu \mathrm{m}$ and are sieved to a size range from 175 to $208 \mu \mathrm{m}$. The particle density is $2.47 \mathrm{~g} / \mathrm{cm}^{3}$. Most of the particles, approximately $95 \%$. appear to be nearly perfect spheres. However, up to about $5 \%$ of the particles are defective. appearing either elliptical or as fragmented pieces of glass. The FCC particles have a mean size of $90 \mu \mathrm{m}$ and are sieved to a size range of $75-105 \mu \mathrm{m}$. They appear to be slightly more aspherical than the glass particles.

The dimensions of the piece of riser wall are $12 \mathrm{~cm} \mathrm{x} 12 \mathrm{~cm}$ with a thickness of $1 \mathrm{~cm}$. It was glued to a piece of plexiglass and then mounted on the top wall of the test section. The dimensions of the glass plate are $27 \mathrm{~cm} \times 27 \mathrm{~cm}$ with a thickness of $3 \mathrm{~mm}$. Support posts are placed at the comers of the plate. The size of the plate and the distance of the support posts from the collision point are sufficient to ensure that the collisions are independent of the finite plate dimensions. This was verified based on the criteria given by Sondergaard et al. (9).

To minimize aerodynamic drag on the particles, the air velocity in the wind tunnel was set to minimize slip velocity between the particles and air. This was verified using a twocomponent LDV to measure air and particle velocities. The maximum slip velocity between the air and particles was verified to be less than $1.3 \mathrm{~m} / \mathrm{s}$ within the region where particle collisions are measured. This gives a Stokes number of 500 (based on the particle response time of $0.13 \mathrm{~s}$ and a particle transit time through the measurement region of $300-400 \mu \mathrm{s}$ ) ensuring that the particle response to drag is negligible. 
Since particle spin isn't measured with the PTV system, it is important to ensure that it doesn't significantly affect the measured parameters. Even if the particles were spinning at very high rotation speeds, for example, more than $10.000 \mathrm{rpm}$, the actual speed of the particle surface due to rotation (the product of angular velocity and particle radius) is less than $1 \%$ of the particle's linear velocity. Therefore, it is assumed that particle spin has a negligible effect on the measured collision parameters. For larger particles and slower velocities, such as those used in (5), (3.18 and $5.99 \mathrm{~mm}$ at $<2 \mathrm{~m} / \mathrm{s}$ ), particle spin can have a significant effect on the collision parameters.

The beam from an acousto-optically modulated argon laser is transmitted through a series of cylindrical lenses to form a thin $(1 \mathrm{~mm})$ sheet of pulsed laser light. The $7 \mathrm{~W}$ beam is directed upward through the base of the test section in the wind tunnel and through the glass plate to illuminate the particle-wall collisions. The pulse repetition rate was set at $25 \mathrm{KHz}$ with a pulse duration of $5 \mu$ s.

As particles pass through the light sheet, they scatter light into a high-resolution (1024 $x 1024$ pixel) video camera positioned at a right angle to the laser sheet. This produces a multiple-exposure picture showing aseries of images of a particle along its trajectory. Figure 2 shows an example picture of a particle colliding with the glass plate. The field-of-view size for these measurements was $28.38 \times 21.57 \mathrm{~mm}$. The PTV pictures are digitized at 30 pictures/ second with 8-bit (256 levels) gray-scale resolution into a SUN 670 computer with an ANDROX parallel image-processor. Only a $2.69 \mathrm{~mm}$ region of the PTV picture near the wall (as shown in Figure 2) is permanently stored. Particle images are detectable within one particle image diameter of the plate surface.

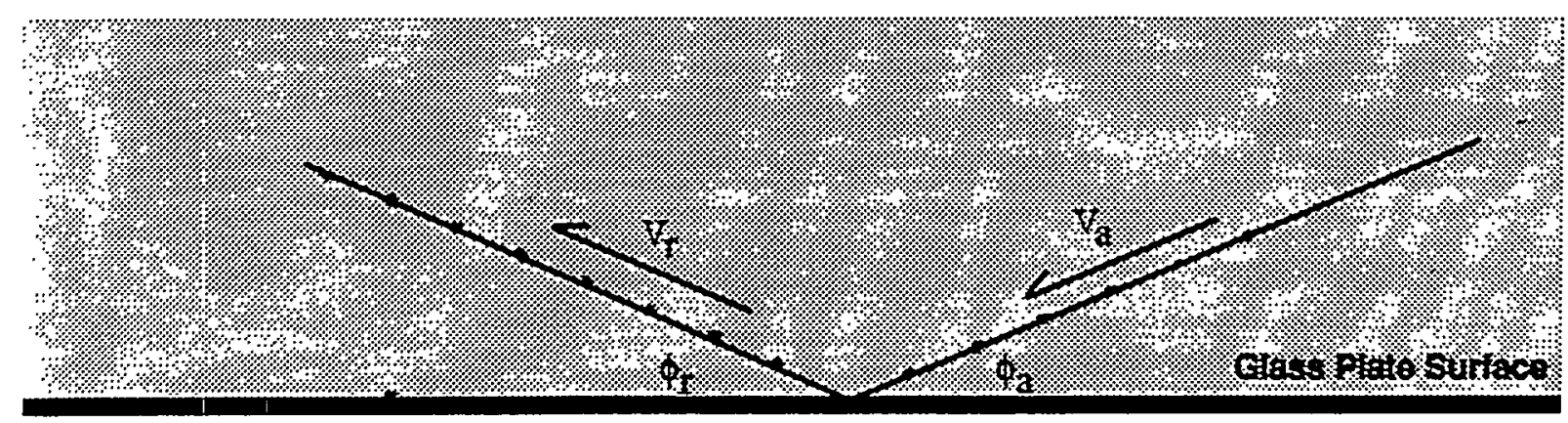

Figure 2. Typical particle wall collision. A black line is added to show the location of the glass plate.

Software has been developed at PETC to automatically analyze multiple-exposure pictures of particle trajectories $(10,11)$. The first step in the analysis is recognition of particle images and calculation of image centroids. The next step is to recognize groups of centroids as belonging to an approach or rebound trajectory. This is achieved using an iterative Kalman filtering algorithm with a likelihood function based on knowledge of the number of particle images along a trajectory. Next, the approach and rebound trajectories are extrapolated to their intersection points with the glass plate. If the points where a pair of trajectories intersects the plate are close, within an adjustable tolerance, they are assumed to be from the same particle. For this work, this tolerance was set at two particle diameters. This tight tolerance restricts the data to particles with instantaneous contacts with the plate; particles that slide or roll upon contact are automatically excluded. Sliding or rolling appears to happen only with a small fraction of the glass particles that appear to be aspherical. The last step in the analysis process 
involves calculation of angles, velocities, and restitution coefficients. The angles and velocities were extracted based on the displacement of the first and fifth images closest to the wall; therefore, the measurements presented here are very close to the wall, usually within $1 \mathrm{~mm}$. The entire image acquisition and analysis process takes about one second per picture thus enabling rapid analysis of the thousands of trajectories required for statistical convergence.

The experimental uncertainties in collision parameters (velocity, angle, and restitution coefficients) arise from two factors: uncertainties in the basic measurements of distance with the imaging system and uncertainties in the timing of laser pulses. The digital pulse generator used in this experiment has one nanosecond resolution making the timing uncertainty negligible. The uncertainty in distance is mainly due to the pixel resolution of the imaging system and the resolution of the scale used to calibrate the imaging system. For this PTV system and experimental conditions, the total uncertainty in distance measurement is $\pm 35 \mu \mathrm{m}$. This translates into an uncertainty of $\pm 0.22 \mathrm{~m} / \mathrm{s}$ in velocity, $\pm 0.6^{\circ}$ in angle, $\pm 5 \%$ in normal restitution coefficient, and $\pm 2 \%$ in tangential coefficient of restitution.

\section{RESULTS AND DISCUSSION}

Figures 3 and 4 show the dependence of the tangential and normal coefficient of restitution ( $\beta$ and $e$, respectively) on approach velocities, $v_{a}$, and approach angle, $\phi_{a}$ for the glass particles and glass plate system. Values for the mean, standard deviation and experimental uncertainties for all measured and calculated parameters for both systems are given in the table below. It is interesting to point out that the values of e are larger than unity for the FCC-riser wall system. This is due to large-scale roughness of the wall. The reduction of $\beta$ is assumed to be due to the small-scale roughness of the wall.

\begin{tabular}{|c|c|c|c|c|c|}
\hline & \multicolumn{2}{|c|}{ mean } & \multicolumn{2}{|c|}{ standard deviation } & \multirow[t]{2}{*}{ uncertainty } \\
\hline & glass & $F C C$ & glass & FCC & \\
\hline Rebound velocity, $v_{i}$ (m/s) & 16.10 & 15.56 & 1.21 & 2.87 & 0.22 \\
\hline Approach velocity, $v_{a^{\prime}}(\mathrm{m} / \mathrm{s})$ & 17.07 & 21.22 & 1.29 & 3.41 & 0.22 \\
\hline Rebound angle, $\varphi_{,}\left({ }^{\circ}\right)$ & $17.94^{\circ}$ & $21.26^{\circ}$ & $1.84^{\circ}$ & $9.21^{\circ}$ & $0.6^{\circ}$ \\
\hline Approach angle, $\varphi_{\mathrm{a}},\left(^{\circ}\right)$ & $17.5^{\circ}$ & $14.87^{\circ}$ & $1.25^{\circ}$ & $1.73^{\circ}$ & $0.6^{\circ}$ \\
\hline Normal coefficient of restitution, $e$ & 0.94 & 1.02 & 0.07 & 0.39 & 0.05 \\
\hline Tangential coefficient of restitution, $\beta$ & 0.97 . & 0.7 & 0.02 & 0.11 & 0.018 \\
\hline Coefficient of friction, $\mu$ & 0.027 & & 0.009 & & \\
\hline
\end{tabular}

Figure 5 shows the data for the glass system in terms of a nondimensional approach angle, $\Psi_{1}$, and a nondimensional rebound angle, $\Psi_{2}$, proposed by Maw, Barber and Fawcett $(12,13)$ and defined as

$$
\Psi_{1}=\frac{2(1-v)}{\mu(2-v)} \frac{V_{a, s}}{V_{a, \Omega}} \quad \text { and } \quad \Psi_{2}=\frac{2(1-v)}{\mu(2-v)} \frac{V_{r . s}}{V_{a, n}}
$$

In these equations, $v$ is Poisson's ratio, which is 0.22 for glass particles, $V_{a, t}$ is the tangential approach velocity, $V_{r, t}$ is the tangential rebound velocity, $V_{a, n}$ is the normal approach velocity, $V_{r, n}$ is the normal rebound velocity, and $\mu$ is a coefficient of friction for collisions. 
To calculate the coefficient of friction the following equation is used:

$$
\mu=\frac{V_{u, t}-V_{r, t}}{(1+e) V_{u, n}\left(1+1 / k^{2}\right)}
$$

This equation is valid for the slip regime $(11,12)$ where $\Psi_{1}>4 \chi$. For this experiment, $\chi=0.153$. where $\chi$ is a nondimensional parameter given by

$$
\chi=\frac{(1-v)\left(1+1 / k^{2}\right)}{2-v}
$$

with $\mathrm{k}^{2}$ being a measure of the radius of gyration, which is $2 / 5$ for homogeneous spheres. Using the equations above gives a mean value of 0.027 for $\mu$ with a standard deviation of 0.009 .

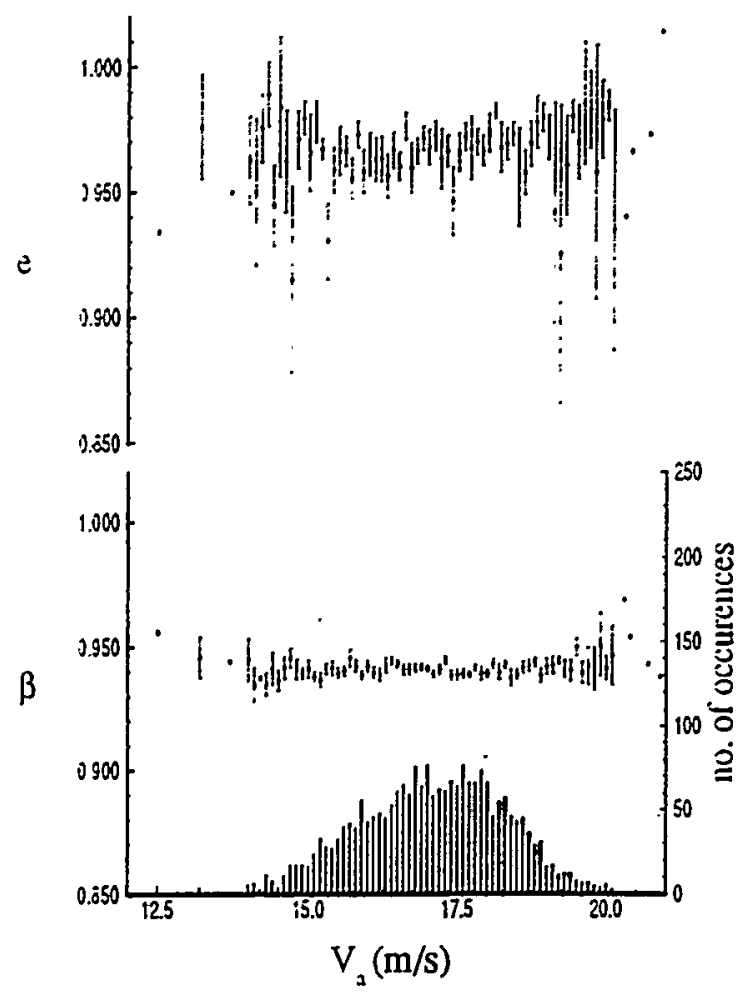

Figure 3. Normal and tangential coefficient of restitution versus approach velocity (Glass particles). Vertical bars show $95 \%$ confidence intervals.

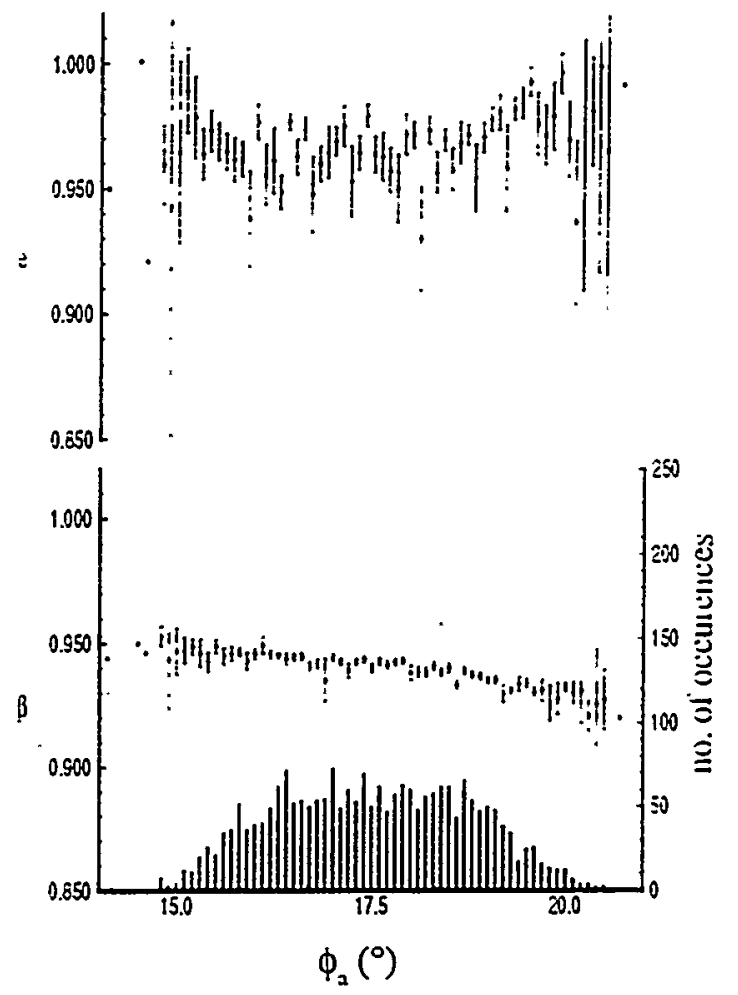

Figure 4. Normal and tangential coefficient of restitution versus approach angle (Glass particles). Vertical bars show $95 \%$ confidence intervals. 
Figures 3 and 4 show that, within the narrow range of approach angles and velocities for this experiment, $e$ is independent of $\varphi_{a}$ and $v_{a}$ for the glass system; however, $\beta$ declines slightly as $\varphi_{a}$ increases. Data presented in Goldsmith (3) show that e varies with $v_{a}$ only for low velocities, $v_{\mathrm{a}}<1 \mathrm{~m} / \mathrm{s}$, where e decreases with $\mathrm{v}_{\mathrm{a}}$.

Figure 7 shows the variation of $\varphi_{\mathrm{r}}$ vs. $\varphi_{\mathrm{a}}$ for both systems. It is obvious that, as expected, the collisions for the glass system are specular. The diffusivity of the collisions for the FCC-riser wall is striking. Future publications will elaborate on the diffuse scattering of particles.

\section{ACKNOWLEDGMENTS}

This work was done under Cooperative Research and Development Agreement No. PC93-006 between the U.S. Department of Energy and Camegie Mellon University (CMU). The authors from CMU wish to gratefully acknowledge funding from the Amoco Oil Company. The important contributions of Bala Kumar of the CMU Robotics Institute and R. Srinivasan of EASI Inc. with image analysis are also acknowledged.

\section{REIERENCES}

1. Yasuna, J., Bolio, E., Gamwo, I. and J. Sinclair, AIChE Symposium Series, 89 (1993) 184.

2. Louge, M., Mastorakos; E. and J. Jenkins, J. Fluid Mech., 231 (1991) 345.

3. Goldsmith, W. "Impact - The Theory and Behavior of Colliding Solids," Edward Amold Publishers, London (1960).

4. Tabakoff, W. and Malak, M.F., "Laser Measurement of Fly Ash Rebound Parameters for Use in Trajectory Calculations," J. Turbomachinary, Vol. 109, Oct. 1987.

5. Foerster, S., Louge, M., Chang, H. and Allia, K. , Physics of Fluids A, submitted for publication.

6. Shaffer, F.D., Ekmann, J.M. and Ramer, E.R., "Development of Pulsed-LaserVelocimetry Systems Utilizing Photoelectric Image Sensors," Proc. of the AIAA/ASME/SIAM/ APS First National Fluid Dynamics Congress, Cincinnati, OH, July 1988.

7. Shaffer, F. and Ramer, E., "Pulsed Laser Imaging of Particle-Wall Collisions," in Proceedings of the International Conference on the Mechanics of Two-Phase Flow, 12-15 June 1989, Taipai, Taiwan (1989) 116.

8. Sommerfeld, M. "Application of Opticai Non-Intrusive Measurement Techniques for Studies of Gas-Solid Flows," ASME Fluids Engineering Meeting, Gas-Solid Flow Symposium, June 1993.

9. Sondergaard, R., Chaney, K. and Brennen, C., ASME J. of Applied Mechanics, 57 (1990) 694.

10. Ramer, E. and Shaffer, F., Applied Optics, 31 (1990) 779.

11. Singh, R., Shaffer, F., and Borovetz, H., "Fluorescent Image Tracking Velocimetry Algorithms for Quantitative Flow Analysis in Artificial Organs," Int. Symp. on Electronic Imaging, San Jose, CA, January 1993.

12. Maw, N., Barbar, J.R., and Fawcett, J.N., "The Oblique Impact of Elastic Spheres." Wear, 38(1), 101-114, 1976.

13. Maw, N., Barbar, J.R. and Fawcett, J.N., "The Role of Elastic Tangential Compliance in Oblique Impact," ASME J. of Lubrication Technology, 103, 74-78, 1981. 


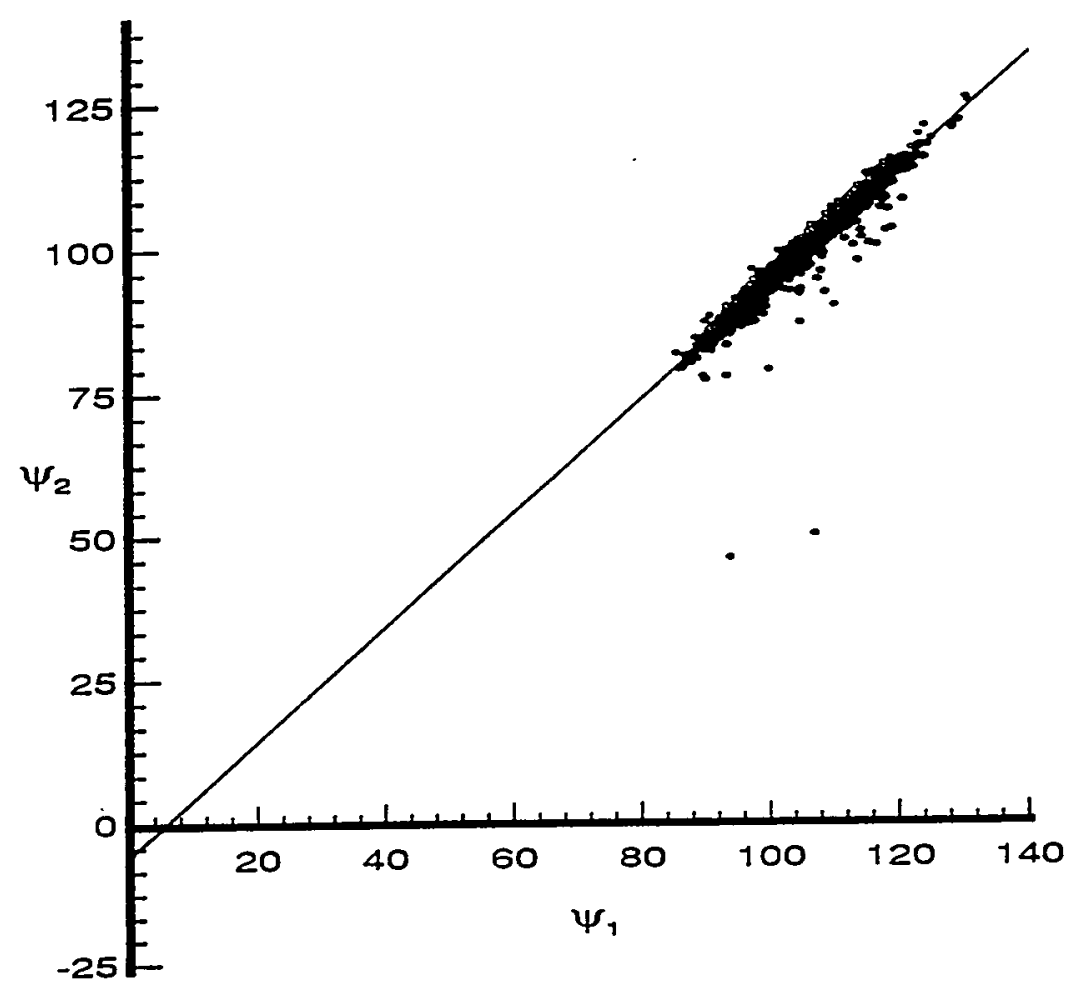

Figure 5. Non-dimensional approach angle versus non-dimensional rebound angle (Glass particles).
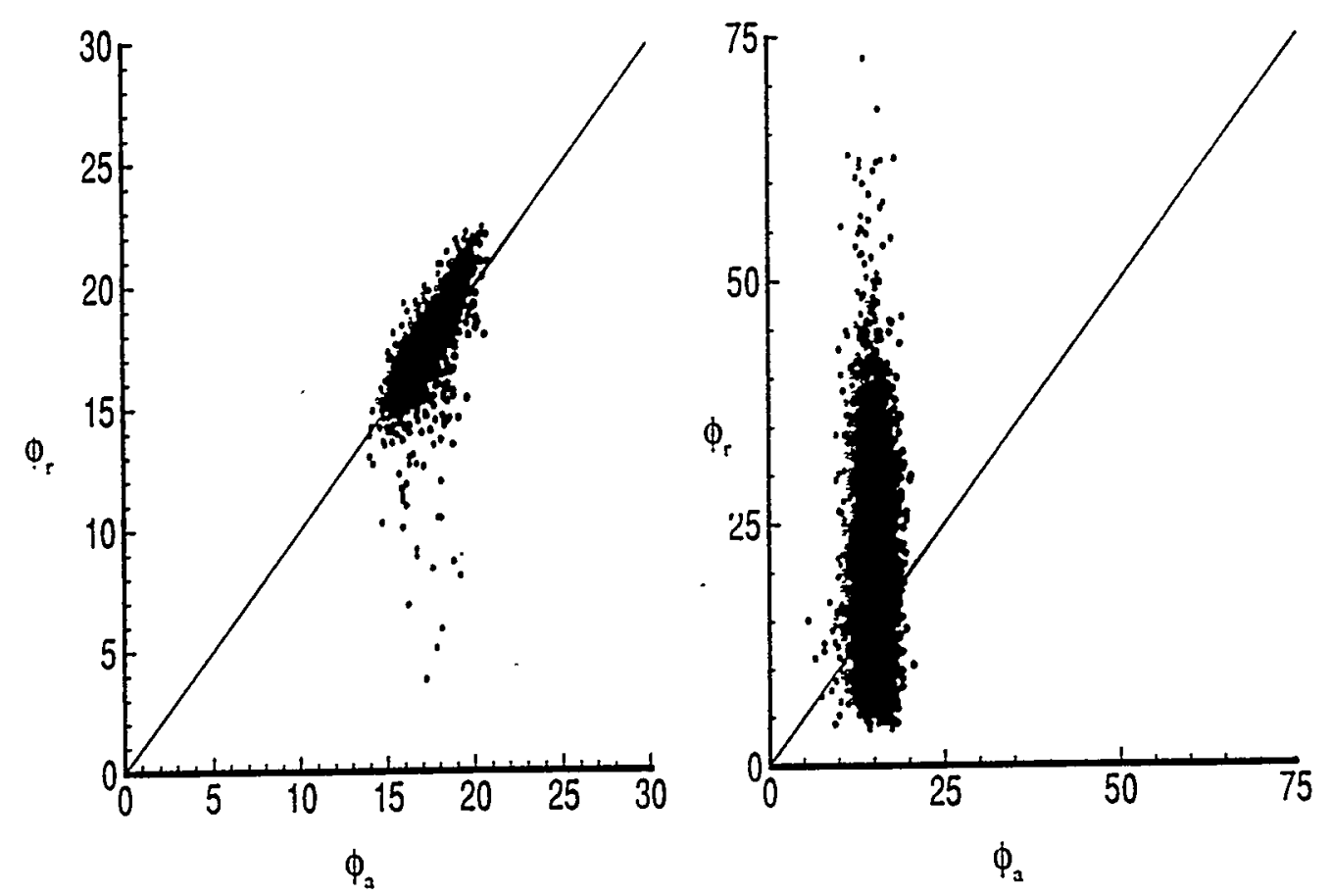

Figure 6. $\varphi_{2}$ vs. $\varphi_{1}$ for glass particle-glass plate system (left) and FCCriser wall system (right) 